\title{
Optimisation of quasi-3D electrical resistivity imaging - application and inversion for investigating heterogeneous mountain permafrost
}

\section{Schwindt and C. Kneisel}

Institute of Geography and Geology, Department of Physical Geography, University of Würzburg, Am Hubland, 97074 Würzburg, Germany

Received: 3 October 2011 - Accepted: 9 November 2011 - Published: 5 December 2011 Correspondence to: D. Schwindt (daniel.schwindt@uni-wuerzburg.de)

Published by Copernicus Publications on behalf of the European Geosciences Union.

TCD

5, 3383-3421, 2011

Optimisation of quasi-3D ERI for permafrost studies

D. Schwindt and
C. Kneisel

\section{Title Page}

\section{Abstract}

Conclusions

Tables

14

$\triangleleft$

Back

Full Screen / Esc

Printer-friendly Version

Interactive Discussion 


\section{Abstract}

This study aimed to optimise the application, efficiency and interpretability of quasi-3D resistivity imaging for investigating the heterogeneous permafrost distribution at mountain sites by a systematic forward modelling approach. A three dimensional geocry-

5 ologic model, representative for most mountain permafrost settings, was developed. Based on this geocryologic model quasi-3D models were generated by collating synthetic orthogonal 2D arrays, demonstrating the effects of array types and electrode spacing on resolution and interpretability of the inversion results. The effects of minimising the number of $2 \mathrm{D}$ arrays per quasi-3D grid were tested by enlarging the spacing between adjacent lines and by reducing the number of perpendicular tie lines with regard to model resolution and loss of information value. Synthetic and measured quasi3D models were investigated with regard to the lateral and vertical resolution, reliability of inverted resistivity values, the possibility of a quantitative interpretation of resistivities and the response of the inversion process on the validity of quasi-3D models. Results 15 show that setups using orthogonal 2D arrays with electrode spacings of $2 \mathrm{~m}$ and $3 \mathrm{~m}$ are capable of delineating lateral heterogeneity with high accuracy and also deliver reliable data on active layer thickness. Detection of permafrost thickness, especially if the permafrost base is close to the penetration depth of the setups, and the reliability of absolute resistivity values emerged to be a weakness of the method. Quasi-3D imaging has proven to be a promising tool for investigating permafrost in mountain environments especially for delineating the often small-scale permafrost heterogeneity, and therefore provides an enhanced possibility for aligning permafrost distribution with site specific surface properties and morphological settings.

\section{Introduction}

25 Distribution and characteristics of permafrost in both, mountainous and polar regions are a result of the site specific ground thermal regime. In mountainous regions in

\section{Optimisation of quasi-3D ERI for permafrost studies}

D. Schwindt and C. Kneisel

Title Page

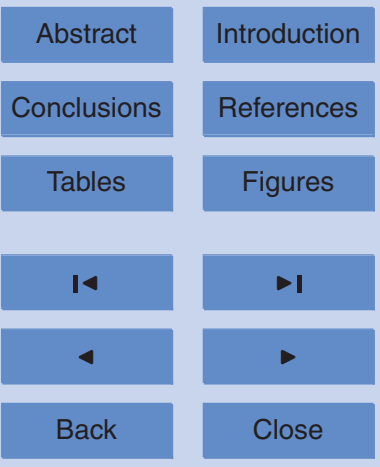

Full Screen / Esc

Printer-friendly Version

Interactive Discussion 
particular, permafrost distribution is characterised by a small scale heterogeneity induced by, besides climatic and microclimatic conditions, a variety of factors including solar radiation, as a result of topography and aspect, snow cover, surface and subsurface material, but also vegetation cover and soil/humus characteristics. Delineation

5 of the three dimensional distribution of mountain permafrost in the shallow subsurface greatly assists with understanding of permafrost related processes, and the ground thermal regime as well as geotechnical problems, especially in the context of claims of climatic change and subsequent permafrost degradation.

Over recent decades geophysical methods and, in particular electrical resistivity to10 mography (ERT) have proven to be valuable tools for investigating permafrost related problems in mountainous and polar regions (Hauck and Vonder Mühll, 2003a; Kneisel et al., 2008). The application of geophysics in the study of permafrost takes account of significant changes in the physical properties of earth material that occur at temperatures only slightly lower than $0^{\circ} \mathrm{C}$ (Scott et al., 1990).

15 Even though techniques for 3Dimensional electrical resistivity imaging were developed during the 1990s (Dahlin and Loke, 1997; Loke and Barker, 1996) 2D ERT is still state of the art as a minimal invasive method in the study of permafrost. However, while 2D ERT has proven to be a valuable tool for detecting permafrost and for monitoring its temporal variability (e.g. Hilbich et al., 2009; Hauck, 2002; Krautblatter and 20 Hauck, 2007; Krautblatter et al., 2010; Kneisel et al., 2008; Kneisel, 2004) there are drawbacks in detecting the spatial permafrost heterogeneity. Here 3D-techniques enable direct linking between surface conditions (debris size, solar radiation, vegetation, humus layer thickness) and subsurface- and permafrost characteristics. To date, studies applying 3D-ERT techniques for permafrost related problems are sparse (Schwindt 25 and Kneisel, 2009; Schwindt, 2007; Krautblatter, 2008; Rödder and Kneisel, 2011). In contrast, 3D techniques are generally more common in disciplines such as environmental (Dahlin et al., 2002; Chambers et al., 2007; Bentley and Gharibi, 2004; Bichler et al., 2004; Friedel et al., 2006) hydrological (Park, 1998) and soil science (Garré et al., 2011), as well as geotechnical engineering (Fischanger et al., 2007), investigation

\section{Optimisation of quasi-3D ERI for permafrost studies}

D. Schwindt and C. Kneisel

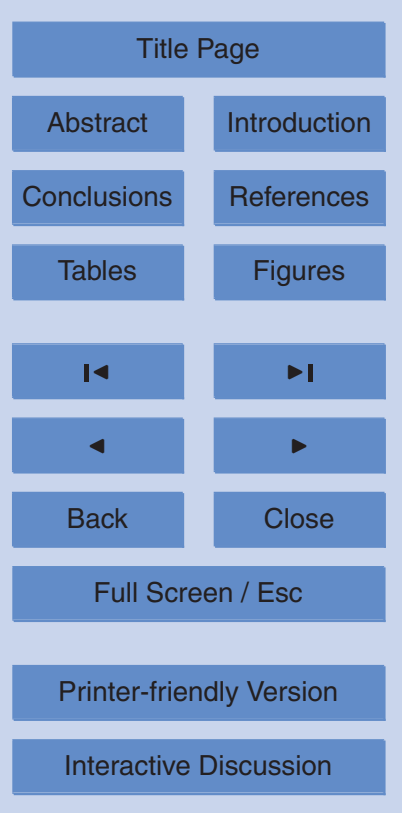


of contaminated and waste disposal sites (Rucker et al., 2009; Soupios et al., 2007) and in archaeology (Papadopoulos et al., 2007; Morelli et al., 2004).

It should be noted that there are inconsistencies in the use of the term "3D" for electrical resistivity studies in the publications mentioned above. Loke (2010) and Loke 5 and Barker (1996) proposed that a true areal 3D ERT can be achieved by arranging a square grid of electrodes with the same unit electrode spacing in $\mathrm{x}$ - and $\mathrm{y}$-direction. Measurements are conducted along the $x$-direction, the $y$-direction and diagonally. Loke (2010) also proposed a second option, which is to collate a series of orthogonal measured 2D ERT surveys into one data file. This option is in many cases also 10 contemplated as "3D", even though no diagonal measurements are taken. Further differentiations must then be made concerning the inversion process. Papadopoulos et al. (2006) differentiate between the "quasi-3D" case, where inverted 2D models are merged to form a quasi-3D model and the "3D" case, where 2D profiles are merged and inverted afterwards, using a three dimensional inversion algorithm. Data sets pre15 sented in most of the literature mentioned above are generated based on the second case, while Bichler et al (2004) simply illustrate their 2D images in a 3D fence diagram. In our opinion the use of the term 3D for collated 2D datasets - even if inverted using a 3D algorithm - results in misunderstandings, as measurements are conducted only in $x$ - and $y$-direction, with no measurements at an angle to the grid lines. For a three dimensional model consisting of parallel profiles, only, Loke (2010) used the term "poor man's" 3D. For clarity, we suggest the use of the term quasi-3D for three dimensional models consisting of a number of merged $2 \mathrm{D}$ datasets that are inverted using a $3 \mathrm{D}$ inversion algorithm.

"Real-3D" applications for studying permafrost related problems are uneconomic in 25 most cases. For mapping permafrost in mountain environments a grid size of at least $70 \times 70 \mathrm{~m}$ will be of interest in order to cover a sufficient area and to achieve an adequate depth penetration. This results in 1296 electrode positions for a "real-3D" grid (values exemplarily for setups using $36 \times 36$ electrodes and $2 \mathrm{~m}$ unit electrode spacing), which is not practicable in alpine environments due to logistics and time-efficiency

\section{Optimisation of quasi-3D ERI for permafrost studies}

D. Schwindt and C. Kneisel

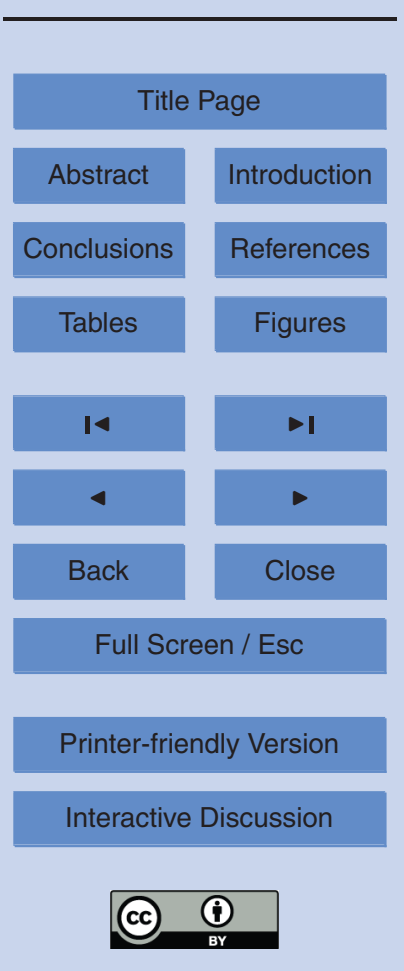


constraints. Here the application of the quasi-3D technique where a number of individually measured 2D ERT surveys are collated possesses distinct advantages.

The quasi-3D technique has been tested previously using forward modelling and presenting case studies for archaeological (cf. Papadopoulos et al., 2006) and envi5 ronmental (cf. Gharibi and Bentley, 2005) problems. However, the assumptions for permafrost related problems differ greatly from those drawn in these studies regarding grid size, aimed resolution, resistivity contrasts in the subsurface as well as size and structure of the object of investigation. Most mountain permafrost sites are more difficult to access and are characterized by a heavy terrain and complex topography, 10 where the optimal installation of electrodes can be challenging. The aim of the study was therefore to optimise quasi-3D imaging for permafrost related problems by forward modelling. The purpose was to achieve best agreement between model resolution and efficiency of data acquisition through creating a series of synthetic quasi-3D images to test the effect of array type, electrode and line spacing as well as the relevance of 15 perpendicular tie lines.

The main focus was on the efficacy of different grid setups for (1) correctly illustrating the modelled high resistive structures and (2) resistivity values, but also for detecting (3) active layer thickness and (4) location of the permafrost base. The accurate reproduction of subsurface resistivity values and resistivity contrasts was analysed in terms of the interpretability of high resistive structures and the possibility of a quantitative interpretation approach (e.g. ice content, temperature). In addition the effects of applying different inversion parameters to the synthetic models with special focus on the convergence criterion on the inversion result were tested.

To verify the assumptions drawn from synthetic modelling and to extend the inter25 pretability of results a quasi-3D image of a permafrost site below the timberline is presented. Particular attention has been paid to the trade-off between minimising the number of array lines and resolution, applicability of array types and the possibility of quantitatively interpreting permafrost characteristics.

\section{Optimisation of quasi-3D ERI for permafrost studies}

D. Schwindt and C. Kneisel

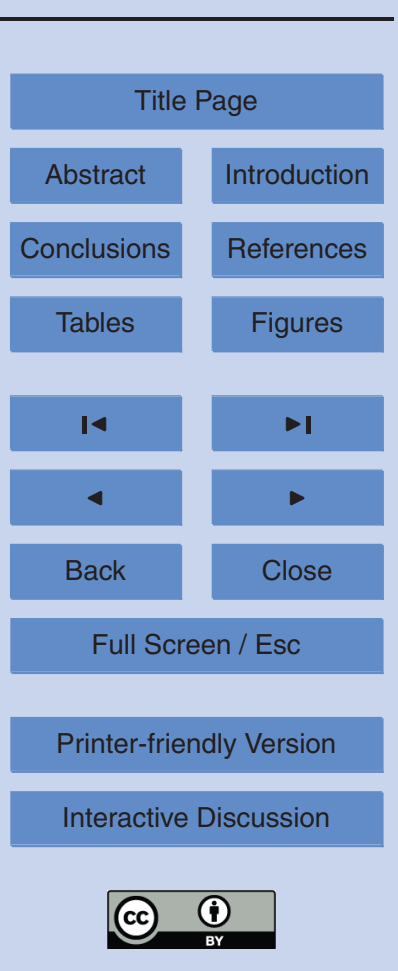




\section{Methods}

\subsection{Forward and inverse modelling - back-and-forth interpretation procedure}

The forward and inverse problems in geophysics have been discussed by various authors (e.g. Hilbich et al., 2009; Friedel, 2003; Scales and Snieder, 2000; Fortier et al., 5 2008; Oldenburg and Li, 1999), with the inverse problem trying to deduce specific earth properties from measurements and the forward problem trying to predict geophysical data from a model of the subsurface. While solutions of the inverse problem are nonunique those of the forward problem are unique (with the existence of only one solution that is capable of representing the data). Consequently, forward modelling of synthetic data enables the evaluation of the aspired resolution of features of interest, the depth of investigation and the occurrence of inversion artefacts by investigating the response of the inversion process to a given structure (Hilbich et al., 2009). The concept of a back-and-forth interpretation procedure is discussed by Fortier et al. (2008) for optimising the field procedure and for enhancing the interpretability of the inversion results of measured resistivity data. Forward modelling of synthetic resistivity data - representing a geocryological model based on prior information from field investigations and knowledge of site characteristics and landforms - can be used for choosing the ERT design (array type, array length, electrode spacing) and as a reference to the inversion results of observed resistivity data.

\subsection{Synthetic 3D subsurface model and grid arrangement}

The approach of the back-and-forth interpretation procedure (Fortier et al., 2008) was adapted to quasi-3D resistivity imaging, to test the effect of different set ups of orthogonal 2D ERT surveys (array type, electrode spacing, line spacing, number of perpendicular tie lines) on the quality and interpretability of the resulting quasi-3D image and the ability to detect high resistive structures. A geocryologic subsurface model was generated (Fig. 1), based on analysis of numerous ERT surveys measured at mountain sites
5, 3383-3421, 2011

Optimisation of quasi-3D ERI for permafrost studies

D. Schwindt and

C. Kneisel

Title Page

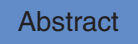

Introduction

Conclusions

References

Tables

Figures

14

$<$

Back

Close

Full Screen / Esc

Printer-friendly Version

Interactive Discussion 
with permafrost (Schwindt and Kneisel, 2010; Kneisel and Schwindt, 2008; Kneisel et al., 2000; Kneisel, 2004). This model tries to reproduce the small scale subsurface heterogeneity, with frozen and unfrozen material and varying permafrost characteristics (ice/liquid water content) of mountain permafrost sites. High resistive bodies $5 \quad(30-170 \mathrm{k} \Omega \mathrm{m})$ are embedded in a matrix of $2 \mathrm{k} \Omega \mathrm{m}$, representing coarse grained talus material and $0.5 \mathrm{k} \Omega \mathrm{m}$ for the finer grained material at the foot of the slope. Modelled structures vary in dimension size, with an active layer thickness of $2 \mathrm{~m}$, and a permafrost base between 5 and $10 \mathrm{~m}$ depth assumed for the geocryologic model. All modelled high resistive structures are located in the lower half of the grid, typical for 10 permafrost settings in talus slopes below the timberline, where the permafrost bodies are usually located towards the foot of the slope.

In order to map permafrost occurrences using 2D and 3D ERT compromises have to be made regarding the choice of electrode spacing and array type. Besides information on permafrost characteristics, factors of interest are the areal distribution, active 15 layer thickness and location of the permafrost base. While small spacings $(<2 \mathrm{~m})$ have advantages in illustrating the active layer, spacings of $\geq 2 \mathrm{~m}$ are favourable for detecting permafrost thickness and for mapping larger areas. The choice of array type at mountain permafrost sites is often a trade-off between resolution and robustness, as achieving an optimal electrode coupling can be challenging. Regarding error proneness the robust Wenner and Wenner-Schlumberger arrays provide more stable resistivity data (e.g. Krautblatter and Verleysdonk, 2008) and yield higher signal to noise ratios (e.g. Hauck and Vonder Mühll, 2003b) compared to the dipole-dipole array. However, while Wenner and Wenner-Schlumberger arrays have advantages in delineating horizontal structures (permafrost base and table) the double dipole array is more sensitive to horizontal changes in resistivity and therefore a good tool for mapping vertical structures (e.g. Fortier et al., 2008; Loke, 2010).

Grid size of quasi-3D measurements is limited by electrode spacing and number of electrodes per 2D array, but can be extended using a roll-along technique (Loke, 2010). For creating the initial models $2 \mathrm{D}$ arrays with 36 electrodes and $2 \mathrm{~m}, 3 \mathrm{~m}$ and

\section{Optimisation of quasi-3D ERI for permafrost studies}

D. Schwindt and C. Kneisel

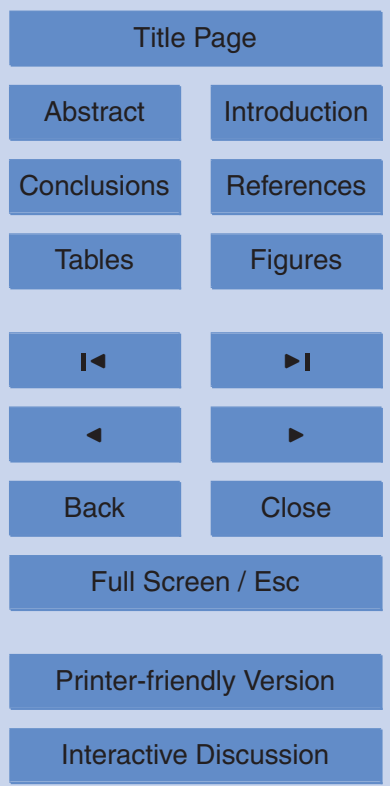


$5 \mathrm{~m}$ electrode spacing were used for the arrays in y-direction. To extend the number of electrodes in $\mathrm{x}$-direction application of a $2 \mathrm{D}$ roll-along technique was presumed for the $2 \mathrm{~m}$ and $3 \mathrm{~m}$ arrays. Dimension parameters of the different setups are given in Table 1 (cf. Fig. 1).

\section{2.3 Quasi-3D data processing and inversion}

A total of 96 quasi-3D models were created using a number of synthetic 2D arrays testing the influence of electrode- (in-line) spacing $(2 \mathrm{~m}, 3 \mathrm{~m}$ and $5 \mathrm{~m})$, line-spacing between adjacent arrays (double, triple and quadruple electrode spacing), number and orientation of lines in y- and x-directions (cf. Fig. 2) and choice of array type (Wenner,

10 Wenner-Schlumberger, dipole-dipole) on the inversion results. Due to limited space not all quasi-3D models are presented. The software package RES2DMOD (Loke, 2002) was used for specifying subsurface resistivities for each $2 D$ section according to the geocryologic model. Corresponding apparent resistivity pseudosections were calculated using the finite-difference method (Dey and Morrison, 1979; Loke, 1994) for the array types Wenner, Wenner-Schlumberger and Dipole-Dipole. $3 \%$ of random noise was added to each synthetic 2D array to reproduce field conditions.

Each of the 96 quasi-3D datasets was created by collating a number of synthetic 2D sections (cf. Table 1) using RES2DINV (Loke, 2010). Within RES3DINV (Loke, 2010) the datasets were inverted using a true three dimensional inversion algorithm, 20 that allows the model resistivity values to vary in all three dimensions. To preclude smoothing of sharp resistivity boundaries robust inversion was applied (Loke et al., 2003). The datasets were inverted using 5 iterations and only minor modifications on the standard inversion settings given by RES3DINV, with small damping factors (initial value for $\lambda=0.1$ ) to obtain a high data consistency of the model. For achieving a 25 reasonable computing time the Incomplete Gauss-Newton optimisation method (Loke and Dahlin, 2002) with high accuracy of $1 \%$ was applied. To provide better resolution, width and thickness of the model blocks of the top few layers were divided by half.

\section{Optimisation of quasi-3D ERI for permafrost studies}

D. Schwindt and C. Kneisel

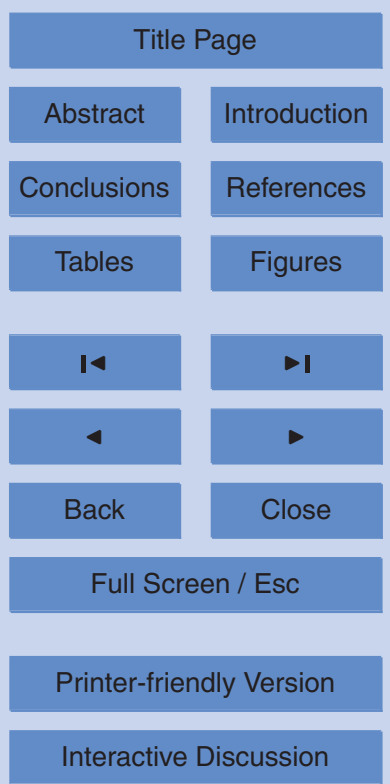




\section{Results}

\subsection{Horizontal model resolution}

To test the horizontal resolution of the different setups (Fig. 3), the depth slices between $3 \mathrm{~m}$ and $5 \mathrm{~m}$ depth were compared for all configurations with a complete $\mathrm{x} / \mathrm{y}$-grid

5 (Wenner, Wenner-Schlumberger and double dipole arrays with $2 \mathrm{~m}, 3 \mathrm{~m}, 5 \mathrm{~m}$ electrode spacing and double, triple and quadruple line spacing). At this depth level all modelled resistivity structures of the geocryologic model were represented. With regard to array length and model cell size the quasi-3D images differ in size and depth of the slices (3-4 $\mathrm{m}$ depth for $2 \mathrm{~m}$ and $3 \mathrm{~m}, 3.5-5 \mathrm{~m}$ for $5 \mathrm{~m}$ electrode spacing) for varying electrode spacing. While all quasi-3D models were inverted using 5 iterations, the third iteration was chosen as the best agreement to the geocryologic model.

All setups were able to detect the main high resistive structures, but there were strong differences in their ability to correctly reproduce size and default resistivity values of the structures as well as the resistivity contrasts to the matrix. As expected, the double dipole array had a higher accuracy in horizontal resolution in all configurations compared to the Wenner and Wenner-Schlumberger arrays. Best agreement between inverted and geocryologic model was for the $2 \mathrm{~m}$ and $3 \mathrm{~m}$ dipole-dipole models, where even the use of quadruple line spacing provided better results than the setups using Wenner and Wenner-Schlumberger configurations. However, good results were 20 achieved using Wenner and Wenner-Schlumberger arrays with an electrode spacing of $2 \mathrm{~m}$ (for all grid setups) and $3 \mathrm{~m}$ (double and triple line spacing) even though the contrast between high resistive features and the matrix was less sharp than for the double dipole arrays. Nonetheless, differences between Wenner and Wenner-Schlumberger arrays were surprisingly marginal considering the considerably higher number of datum points for the Wenner-Schlumberger array (cf. Table 1). The main weakness for both arrays was in illustrating small resistive bodies in close distance in the left part of the quasi-3D images. While the $2 \mathrm{~m}$ as well as the $3 \mathrm{~m}$ arrays with double and triple line spacing were able to differentiate between the anomalies - even though boundaries
5, 3383-3421, 2011

Optimisation of quasi-3D ERI for permafrost studies

D. Schwindt and C. Kneisel

Title Page

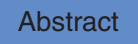

Introduction

Conclusions

Tables

References

Figures

14

4

Back

Close

Full Screen / Esc

Printer-friendly Version

Interactive Discussion 
were blurry - the anomalies merged in the $3 \mathrm{~m}$ quadruple and the $5 \mathrm{~m}$ models. Large and isolated resistive bodies are well imaged for the $5 \mathrm{~m}$-arrays but especially small structures in close distance tend to blur together (Fig. 3; x-direction $0 \mathrm{~m}-40 \mathrm{~m}$ ). The two small anomalies between meters 40 and 50 in x-direction ( $10 \times 10 \mathrm{~m}$ each) were clearly 5 underestimated in size and resistivity for the $5 \mathrm{~m}$ Wenner and Wenner-Schlumberger arrays. These effects were also visible, even though less pronounced, for the $5 \mathrm{~m}$ double dipole arrays.

\subsection{Vertical model resolution}

Knowledge of the ability of different setups to resolve vertical structures is of great interest in permafrost studies to enhance the interpretability of geophysical data concerning the location of permafrost base and table. To test the vertical model resolution a set of depth slices along the XZ-plane was chosen exemplarily for the Wenner and double dipole array comparing 2 and $3 \mathrm{~m}$ electrode spacing using triple line spacing (XZ-Plane 1 and 2 in Fig. 4). For a better quantification and comparability of vertical resistivity distribution virtual boreholes of subsurface resistivity values were created at three representative positions (VB1, 2 and 3 in Fig. 4) for the Wenner and dipole-dipole array (2, 3 and $5 \mathrm{~m}$ electrode spacing, triple line spacing). Three representative locations were chosen for the virtual boreholes considering anomaly thickness $(3,4$ and $8 \mathrm{~m})$ and horizontal extent as well as default resistivity values $(30 \mathrm{k} \Omega \mathrm{m}, 70 \mathrm{k} \Omega \mathrm{m}$ and $170 \mathrm{k} \Omega \mathrm{m})$. Dimension sizes of the resistive blocks, as given by the geocryologic model, as well as the position of the virtual boreholes are marked in the XZ-slices. Due to limited space and no considerable advantages regarding data quality in comparison to the Wenner array, the Wenner-Schlumberger array was neglected for this section.

In terms of the ability to detect the top of resistive structures all the setups presented 25 here produced good results. The top of the anomalies show a sharp transition to the conductive matrix above as given in the geocryologic model. The impact of resistivity gradients between anomaly and matrix on boundary conditions (cf. XZ-planes 1 and 2 and the virtual boreholes in Fig. 4) was comparably low. In contrast, detection of the

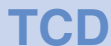

$5,3383-3421,2011$

\section{Optimisation of quasi-3D ERI for permafrost studies}

D. Schwindt and C. Kneisel

Title Page

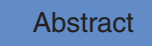

Introduction

Conclusions

Tables

References

Figures

14

4

Back

Close

Full Screen / Esc

Printer-friendly Version

Interactive Discussion 
base of resistive bodies was less consistent for the different setups and appears to be influenced by dimensions as well as resistivity values of the structures.

While all arrays produced good results in detecting the dimension size of shallow structures weaknesses are visible for resistive bodies with thicknesses of more than

$56 \mathrm{~m}$ (base at 8-10 $\mathrm{m}$ depth). Especially in the case of large structures (width $>20 \mathrm{~m}$ ) the thickness is clearly overestimated (cf. VB3). The degree of overestimation is higher for the double dipole array and for small electrode spacings in comparison to the Wenner array and electrode spacings of $\geq 3 \mathrm{~m}$. In case of the small structure $(10 \times 10 \times 4 \mathrm{~m}$, $70 \mathrm{k} \Omega \mathrm{m}$ ) investigated in VB2 the double dipole array provided better results than the

10 Wenner array which underestimated structure size and resistivity for the arrays using 2 and $3 \mathrm{~m}$ electrode spacing. In comparison the double dipole arrays overestimated resistivities by $50 \mathrm{k} \Omega \mathrm{m}(2 \mathrm{~m}$ electrode spacing) and $95 \mathrm{k} \Omega \mathrm{m}$, respectively. Using $5 \mathrm{~m}$ electrode spacing the structure was clearly underestimated in size and resistivity (cf. VB2 and Fig. 3).

15 The lowest resistivity $(30 \mathrm{k} \Omega \mathrm{m})$ was given in the geocryologic model for VB 1 (dimension size: $22 \times 22 \times 3 \mathrm{~m}$ ). Reasonable results in relation to the structure's thickness were provided by the arrays using 2 and $3 \mathrm{~m}$ electrode spacings. Compared to the top of the anomaly the boundary at its base is less distinct with gradually sinking resistivities. Best results were provided by the Wenner and double dipole arrays using $2 \mathrm{~m}$ electrode spacing.

\subsection{Reproduction of default resistivity values}

The ability to reproduce default resistivity values appears to be a main weakness of all quasi-3D models calculated for this study. Comparing results presented in Figs. 3 and 4 with special focus on the virtual boreholes in Fig. 4 all quasi-3D setups show inconsistencies in correctly reproducing resistivities of modelled anomalies. Reasonable results were achieved regarding resistivity values of the matrix. For specific setups no explicit tendencies in reproducing default resistivity values were evident. High resistive anomalies $(170 \mathrm{k} \Omega \mathrm{m}$, cf. VB3 in Fig. 4) were underestimated by all arrays. Underestimation of

\section{Optimisation of quasi-3D ERI for permafrost studies}

D. Schwindt and C. Kneisel

Title Page

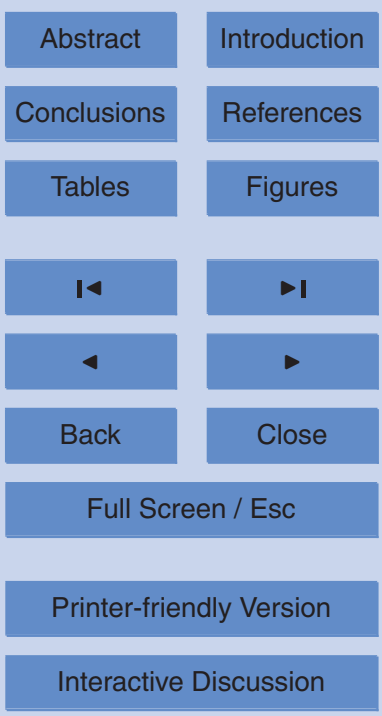


calculated resistivities ranged between $\sim 50 \%$ (Wenner 3 and $5 \mathrm{~m}$ electrode spacing) and $\sim 6 \%$ (Wenner and double dipole, $2 \mathrm{~m}$ electrode spacing). In contrast the double dipole setup with $5 \mathrm{~m}$ electrode spacing overestimated the resistivity by $\sim 200 \%$. The same variability is visible for anomalies with specified low $(30 \mathrm{k} \Omega \mathrm{m})$ and interme5 diate $(70 \mathrm{k} \Omega \mathrm{m})$ resistivity values. Extremely divergent results were produced for the small structure represented in VB2 by the Wenner and double dipole grids using $3 \mathrm{~m}$ electrode spacing. While values were underestimated for the Wenner setup by $74 \%$, resistivity was overestimated by $137 \%$ for the double dipole grid.

In general resistivity values were underestimated by all of the arrays with a high 10 variability in the degree of underestimation. The double dipole setups tended to overestimate resistivities for structures with low and intermediate resistivity values, resulting in almost homogenous resistivity conditions for all modelled structures (Fig. 3), complicating differentiation and interpretation of resistive anomalies. Especially in the case of small resistive structures (VB2, cf. Figs. 3 and 4) the degree of underestimation increased with the application of larger electrode and line spacing (cf. Fig. 3).

\subsection{Approach to increase the efficiency of quasi-3D data acquisition}

Depending on grid size and site characteristics the application of quasi-3D measurements can be challenging and time consuming in mountain environments. To optimise the efficiency of measurements synthetic quasi-3D models were created with a step20 wise decrease in the number of 2D arrays building up the model (cf. Fig. 2) generated by enlarging the parallel line spacing (double, triple, quadruple electrode spacing) and by reducing the number of perpendicular tie lines in the $\mathrm{x}$-direction (half grid; no lines in $\mathrm{x}$-direction). Due to limited space and low variations between Wenner and WennerSchlumberger setups results are presented for the Wenner and double dipole arrays 25 only (Fig. 5).

The results underline the importance of using perpendicular tie lines. Good results were generated by all array types by reducing the number of tie lines by half, using $2 \mathrm{~m}$ and, in some cases, $3 \mathrm{~m}$ electrode spacing. In comparison the geocryologic model

\section{Optimisation of quasi-3D ERI for permafrost studies}

D. Schwindt and C. Kneisel

Title Page

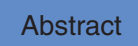

Introduction

Conclusions

Tables

References

Figures

14

4

Back

Close 
was not well reproduced in the synthetic models using only y-lines. Resistive structures were elongated in $\mathrm{x}$-direction with almost seamless transitions between adjacent bodies. The application of $5 \mathrm{~m}$ electrode spacing only yielded acceptable results for the dipole-dipole array using double line spacing (cf. Fig. 5). For all array types the quality

5 of results further debased, when the number of tie lines was reduced. Using larger line spacings boundaries of resistive bodies were blurred and not clearly definable, and small structures are faded.

Regarding the trade-off between data quality and efficiency of measurements, good results were achieved using triple line spacing. In the case of $2 \mathrm{~m}$-arrays the loss in 10 quality of the quasi-3D image in comparison to the application of double line spacing and a full $\mathrm{x} / \mathrm{y}$-grid (Fig. 3) was negligible. The $3 \mathrm{~m}$ grid was capable of correctly detecting most structures. Only in the case of the large resistive structure in the centre of the quasi-3D image boundaries were ragged for both Wenner and dipole-dipole array.

\subsection{Convergence criterion}

15 "Choice of the correct iteration is of great importance for the interpretation of ERTdatasets, as a large number of iterations will tend to overfit data, such that artefacts will result from inversions of the data errors. A small RMS-error does not necessarily correspond to realistic model results" (Hauck and Vonder Mühll, 2003b). For the inversion of synthetic datasets in this study the iteration process was terminated after 5 20 iterations. In the case of synthetic modelling the choice of iteration was based on the best agreement between the inverted and geocryologic model, an approach that is not applicable for measured data.

The effect of a prolonged iteration process is shown in Fig. 6. Presented are all iterations for two depth levels compared to the geocryologic model. The aim was to 25 quantify alterations in shallow depths with default homogenous, low resistive conditions ("active layer") and in high resistive bodies located in deeper layers during the iteration process. Resistivity values were extracted and averaged from two depth layers for three defined areas in the depth level between 4 and $5 \mathrm{~m}$ and their corresponding blocks

\section{Optimisation of quasi-3D ERI for permafrost studies}

D. Schwindt and C. Kneisel

Title Page

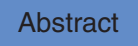

Introduction

Conclusions

Tables References Figures

14

4

Back

Close

Full Screen / Esc

Printer-friendly Version

Interactive Discussion 
in shallow depth (cf. Blocks 1-3 in Fig. 6). One large high resistive area $(170 \mathrm{k} \Omega \mathrm{m}$; Block 1), one small area with lower resistivity values $(30 \mathrm{k} \Omega \mathrm{m}$; Block 2$)$ and Block 3 which represents matrix material with lowest values $(2 \mathrm{k} \Omega \mathrm{m})$ were chosen.

Best agreement between initial and inverted model was accomplished by the third 5 iteration, even though the RMS-error still decreased by almost $4 \%$ towards the fifth iteration. While changes in the resistive structures of depth level 6 were marginal for the fourth and fifth iterations and lead to no improvement of the model, banding effects occurred in depth level 2 . These artefacts clearly correspond to the resistive structures below. Averaged resistivity values of Block 1 (Level 2) increase exponentially between 10 the third and fifth iterations. This effect was visible but not as pronounced for Block 2. In contrast, both depth levels of Block 3 show a similar, constant trend with no artefacts accruing throughout the iteration process. Scattered structures occurring above high resistive structures during a prolonged iteration process can significantly influence the interpretation, especially in view of active layer thickness/permafrost table, but could also be interpreted as a result of bad electrode coupling.

The increase in resistivity values for Blocks 1 and 2 (Level 6) was highest between the first and third iterations. While values for Block 3 (Level 6) were close to the default resistivities $(30 \mathrm{k} \Omega \mathrm{m})$ for iteration 3 and 4 they decreased by almost $10 \mathrm{k} \Omega \mathrm{m}$ towards the fifth iteration. In contrast resistivity values increased slightly between the third and fifth iterations after an exponential increase between the first and third for Block 1 (Level 6) with maximum resistivities far below default values. Results of Hauck and Vonder Mühll (2003b), who showed that especially large resistivity contrast tends to be increased from one iteration to the next without a significant change of the RMS error cannot be confirmed for the quasi-3D case, at least not for the first 5 iterations.

\section{Case study}

Presented here are the results from quasi-3D imaging at a permafrost site below the timberline located in the northern slope of the Val Susauna (upper Engadin, Eastern

\section{Optimisation of quasi-3D ERI for permafrost studies}

D. Schwindt and C. Kneisel

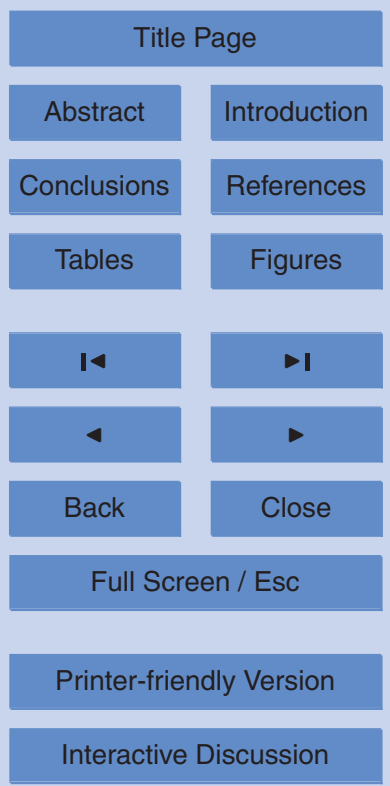


Swiss Alps) close to the village of Susauna. Investigated was the lower parts of the steep talus slope ranging between $1684 \mathrm{~m}$ and $1720 \mathrm{~m}$ a.s.I. where the dolomitic talus material is covered by a thick humus layer of up to $60 \mathrm{~cm}$ thickness. Mean annual air temperature measured in $2 \mathrm{~m}$ height is $2.3^{\circ} \mathrm{C}$. With $0.9^{\circ} \mathrm{C}$ (measured in $5 \mathrm{~cm}$ depth) 5 the mean annual soil temperature is below the critical temperature of $6^{\circ} \mathrm{C}$ (AlvarezUria and Körner, 2007) for significant root growth. Below the timberline permafrost is sporadic and exists only under favourable conditions in small patches that are linked to areas characterised by a differing vegetation mix (dwarfed trees, thick moss cover) and a consistent thick humus layer. Only few sites are known where permafrost has 10 been detected below the timberline (Kneisel et al., 2000; Kneisel and Schwindt, 2008; Delaloye et al., 2003; Kneisel, 2003). At these sites the existence of permafrost is assumed to be the result of a thermal anomaly based on low income of solar radiation, a thick humus layer with a high insulation capability and air circulation inside the talus slope, the so called chimney effect (Wakonigg, 1996; Harris and Pedersen, 1998).

Application of quasi-3D imaging at this site offers the opportunity to test the linkages between surface (vegetation/humus) and subsurface (permafrost) characteristics. As the transition between areas with a "normal" vegetation mix and the area showing dwarf growth is narrow, it was assumed that this is also true for the transition between frozen and unfrozen material. The existence/non-existence of permafrost in close proximity as well as the temporal permafrost variability were confirmed and monitored (own measurements) by joint application of 2D ERT and 2D SRT (seismic refraction tomography). Measurements pointed to a high gradient in resistivity values between frozen and unfrozen material but also to varying resistivity values inside the permafrost body.

The study site in the Val Susauna constitutes a representative site for testing the 25 application of quasi-3D imaging at a permafrost site. Excellent electrode coupling due to the conductive moss/humus layer provided high data quality, low noise ratios and therefore an optimal reliability and interpretability of measured data.

\section{Optimisation of quasi-3D ERI for permafrost studies}

D. Schwindt and C. Kneisel

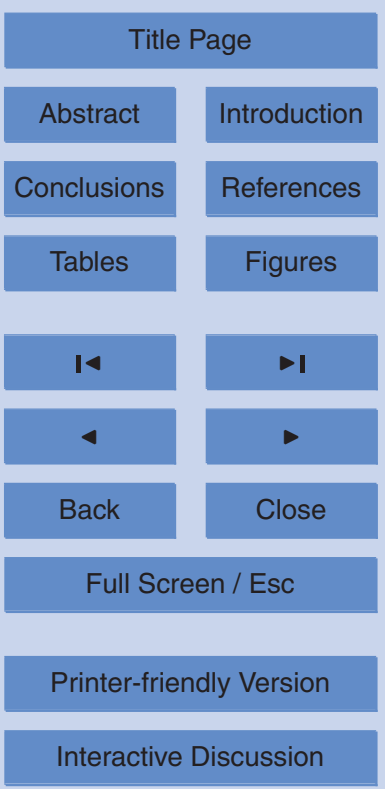




\subsection{Data acquisition and grid setup}

In the summer of 2009 a quasi-3D grid was mapped out consisting of $122 \mathrm{D}$ arrays measured vertically to the scree slope ( $y$-direction) and 5 perpendicular arrays ( $x$ direction) covering the central part of the study site. The grid was extended by another

57 profiles in y-direction in the summer of 2010 (cf. Fig. 7). For data acquisition a Syscal Junior Switch resistivity meter (IRIS Instruments, France) was used, with 36 electrodes per array and an electrode spacing of $2 \mathrm{~m}$ resulting in an array length of $70 \mathrm{~m}$. Triple electrode spacing ( $6 \mathrm{~m}$ line spacing) was used for parallel profiles in y-direction and $10 \mathrm{~m}$ line spacing for profiles in $\mathrm{x}$-direction. Both, dipole-dipole and Wenner arrays were 10 applied. Due to the conductive humus layer electrode coupling did not pose a problem. Topographical information for each electrode position was gathered by recording the absolute elevation for each 2D array. Data acquisition took about 4 days with variable manpower of between 1 and 3 researchers.

\subsection{Data processing and inversion}

15 As described above, the 2D arrays were collated to a quasi-3D dataset and inverted using a true 3D inversion algorithm within RES2DINV/RES3DINV (Loke, 2010). In contrast to the synthetic datasets, inversion parameters were adjusted for the data measured in the field. Banding effects were reduced by using a slightly higher initial damping factor $(\lambda=0.15)$ for the topmost layers and by applying a diagonal roughness filter (Farquharson, 2008). The diagonal component reduced the tendency of the normal horizontal roughness filter to produce structures aligned along the $x$ - and $y$-directions (Loke, 2010). Width and thickness of the model blocks of the the top few layers were divided in half to provide better resolution. The finite-element method (Silvester and Ferrari, 1996) was used, which is preferable for datasets containing optimisation method with an accuracy of $1 \%$ was applied. To preclude smoothing of sharp resistivity boundaries robust inversion was applied.

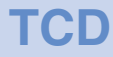

5, 3383-3421, 2011

\section{Optimisation of quasi-3D ERI for permafrost studies}

D. Schwindt and C. Kneisel

Title Page

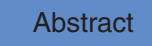

Introduction

Conclusions

Tables

References

Figures

14

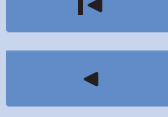

$\rightarrow$

Back

Close

Full Screen / Esc

Printer-friendly Version

Interactive Discussion 
Three quasi-3D models were inverted. Besides the Wenner and the double dipole array the third model was based on the inversion of a dataset created by merging the Wenner and dipole-dipole measurements into one file. This approach tries to combine advantages of both arrays, i.e. the lateral resolution of the double dipole array with the low error proneness and vertical resolution of the Wenner array.

\subsection{Results of the case study}

Presented here are quasi-3D images of the Wenner and double dipole array as well as the combined inversion of both datasets (Fig. 7). Results of the different array types differ marginally with regard to a qualitative interpretation. Through additional measurements (repeated SRT and ERT measurements, ERT monitoring, not presented in this study) the structure has been verified as a permafrost body.

Compared to the double dipole and the combined inversion of both datasets the Wenner setup produced a smoother subsurface model. Especially in shallow depth slightly noisier data are produced by the double dipole and combined Wenner/dipole arrangements. All setups showed a clearly definable high resistive permafrost body in the centre of the models between 1.5 and $7 \mathrm{~m}$ depth that is devided into two main structures by an area with slightly lower resistivities. A sharp transition to low resistive material towards the foot of the slope $(0-10 \mathrm{~m}$ in $y$-direction) but slowly decreasing resistivities uphill are visible. The top of the structure is clearly differentiated from the low resistive material above. In comparison the base of the permafrost body is less clearly defined. Between 6 and $10 \mathrm{~m}$ depth resistivities slowly decrease. The resistive structure is thicker for the double dipole and combined Wenner/dipole arrangement.

A small structure is visible in the top three layers for all arrays (x-direction 30-40 m; $y$ direction 10-30 m), with slightly higher resistivity values. Unlike the largest parts of the investigated talus slope this area was not covered by a conductive moss/humus layer. Due to air cavities, resistivity of the dolomitic material was much higher in comparison to the - up to $70 \mathrm{~cm}$ thick - humus/moss cover. Between 0-30 m (x-direction) an area

\section{Optimisation of quasi-3D ERI for permafrost studies}

D. Schwindt and C. Kneisel

Title Page

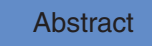

Introduction

Conclusions

Tables

References

Figures

14

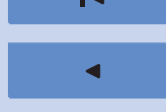

$\rightarrow$

Back

Close 
with low resistivities was detected by all arrays, which corresponds to an area of finer grained material defined by topographical conditions.

While all setups produced good results and coincided well regarding delimitation as well as the qualitative detection of surface and subsurface structures, a quantitative 5 interpretation with regard to ice content and permafrost temperature, without the application of additional methods, is questionable. Resistivities differed strongly between the Wenner and the dipole-dipole setups, with higher values for the latter. The combined inversion of the Wenner and double dipole dataset produced even higher values. A virtual borehole (Fig. 8) was created to compare the data of the quasi-3D model with 10 the measured $2 \mathrm{D}$ datasets at a crossing point.

Surprisingly maximum resistivities of the quasi-3D models were markedly higher than values obtained from the inverted $2 \mathrm{D}$ arrays at the selected crossing point (cf. Fig. 8). Significant differences were visible between the applied array types, but also between the longitudinal profile (measured in y-direction vertical to the slope) and the 15 perpendicular crossing profile. A comparison of the array types demonstrated that maximum values of the double dipole array for the longitudinal profile were higher by $26 \mathrm{k} \Omega \mathrm{m}$ than results of the Wenner measurement. Results of the double dipole array measured in cross direction were about $11 \mathrm{k} \Omega \mathrm{m}$ lower than data of the Wenner array for the same layout. Maximum resistivities were higher for the longitudinal profiles than for the cross profiles, with a larger gap between double dipole measurements ( $48 \mathrm{k} \Omega \mathrm{m}$ ) compared to the Wenner datasets $(11 \mathrm{k} \Omega \mathrm{m})$.

Besides maximum resistivity values the graphs show differences between $2 D$ and $3 D$ inversions in terms of active layer thickness, location of the permafrost base and structure of the permafrost body. Despite of the permafrost table being slightly shallower the permafrost body is much more clearly delineated in the 3D inversion compared to the 2D data, which do not depict the permafrost base as sharply. With almost constant resistivity values the longitudinal Wenner array and the perpendicular double dipole array point to homogenous permafrost conditions between a depth of $\sim 2.5 \mathrm{~m}$ and $\sim 6.5 \mathrm{~m}$. In contrast all other measurements show maximum resistivities at around $3 \mathrm{~m}$ depth,

\section{Optimisation of quasi-3D ERI for permafrost studies}

D. Schwindt and C. Kneisel

Title Page

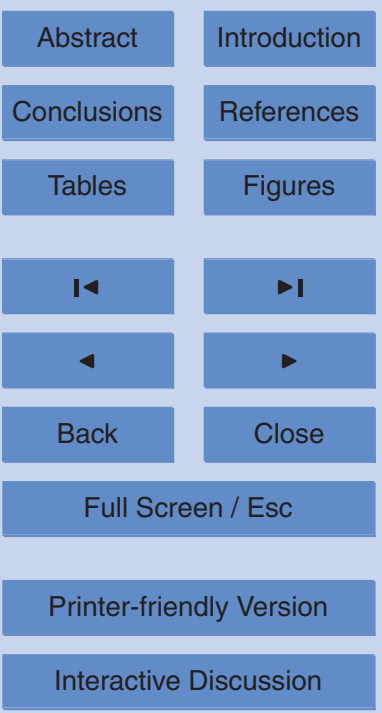


decreasing strongly to values around $10 \mathrm{k} \Omega \mathrm{m}$ to $15 \mathrm{k} \Omega \mathrm{m}$ between 6 and $8 \mathrm{~m}$ depth. Location and characteristics of the permafrost base are not clearly definable, as results are inconsistent for different inversions.

\section{Discussion}

5 Results provided by this study show that quasi-3D ERT is a valuable tool for permafrost related problems, with high potential for permafrost mapping but some drawbacks concerning the quantitative permafrost characterisation. The resolution power of quasi-3D surveys is a function of array type electrode spacing and line spacing as well as the relative size, depth and location of the anomalous bodies with respect to the ERT lines

10 (Gharibi and Bentley, 2005). In contrast to the established fields of application such as environmental (Bentley and Gharibi, 2004) or archaeological (Papadopoulos et al., 2007) studies quasi-3D imaging at mountain permafrost sites constitutes additional challenges due to the often demanding surface characteristics. A trade-off between resolution and efficiency of measurements is of fundamental interest for optimising the application in terms of time- and cost-efficiency.

Good results were provided by setups consisting of 2D arrays with 2 and $3 \mathrm{~m} \mathrm{elec-}$ trode spacings. Even with a massive reduction in the number of arrays per grid reasonable results were achieved regarding the horizontal and vertical model resolution. Best agreement for setups with enlarged line spacing was provided by using triple electrode spacing for adjacent profiles. A further enlargement to quadruple electrode spacing can only be recommended for setups using $2 \mathrm{~m}$ electrode spacing and, ideally choosing the double dipole array. Further optimisation can be achieved by reducing the number of perpendicular tie lines. As shown in Fig. 5 the reduction of tie lines by half provides results comparable to the full $\mathrm{x} / \mathrm{y}$-grid, with best results for $2 \mathrm{~m}$ electrode spacing.

Nonetheless, site characteristics and objectives of the study are fundamental to the setup of quasi-3D grids. Grid setups using electrode spacings of less than $1 \mathrm{~m}$ are not
5, 3383-3421, 2011

\section{Optimisation of quasi-3D ERI for permafrost studies}

D. Schwindt and

C. Kneisel

Title Page

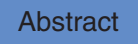

Introduction

Conclusions

References

Tables

Figures

14

4

Back

Close

Full Screen / Esc

Printer-friendly Version

Interactive Discussion 
suitable for most permafrost studies, due to the particularly small grid size and shallow depth of investigation, but might be favourable for detecting areal variations in active layer thickness. While the application of electrode spacings $>3 \mathrm{~m}$ have proven to be incapable of detecting small scale changes in the subsurface (cf. Figs. 4 and 5), it might 5 be useful for obtaining a rough overview of permafrost distribution over a comparably large area and, in some cases, for achieving a higher sounding depth.

Using electrode spacings $\leq 1 \mathrm{~m}$ and single line spacing - meaning line spacing is equal to electrode spacing - Papadopoulos et al. (2006) stated that measurements in only one direction are adequate for producing a valid three-dimensional subsurface 10 image. It is questionable, if a quasi-3D image consisting of only parallel arrays (with line spacing larger than electrode spacing) is capable of reliably reproducing the three dimensional subsurface heterogeneity. As presented (Fig. 5) the lack of perpendicular measurements results in contortions, as well as broadening of structures perpendicular to the line direction, and partially small structures are not detected. The application of 15 perpendicular tie lines has two advantages. (1) To some degree it is a matter of coincidence if a structure of interest is covered by a single 2D array or if it is situated between two adjacent lines. As it is not appropriate to base a measurement on coincidence, this factor can be reduce by minimising the line spacing or by perpendicular measurements that record subsurface conditions between adjacent lines. (2) Block size of the quasi3D subsurface model depends on electrode spacing and parallel line spacing. Applying $2 \mathrm{~m}$ electrode spacing and $6 \mathrm{~m}$ line spacing with no perpendicular tie lines results in a model block size of $2 \mathrm{~m} \times 6 \mathrm{~m}$. By using tie lines, model block dimension in cross direction is not based on line spacing but on electrode spacing of perpendicular tie lines, resulting in a block size of $2 \times 2 \mathrm{~m}$. As a result additional information on the subsurface is gained and resolution of the subsurface model is optimised.

The grid setup of the field example (Fig. 7) constitutes a further trade-off for minimising the number of 2D arrays. This optimisation was based on knowledge of site characteristics and single 2D-measurements (ERT, SRT) applied in advance. Perpendicular profiles were arranged in the centre of the grid, where highest model resolution was

\section{Optimisation of quasi-3D ERI for permafrost studies}

D. Schwindt and C. Kneisel

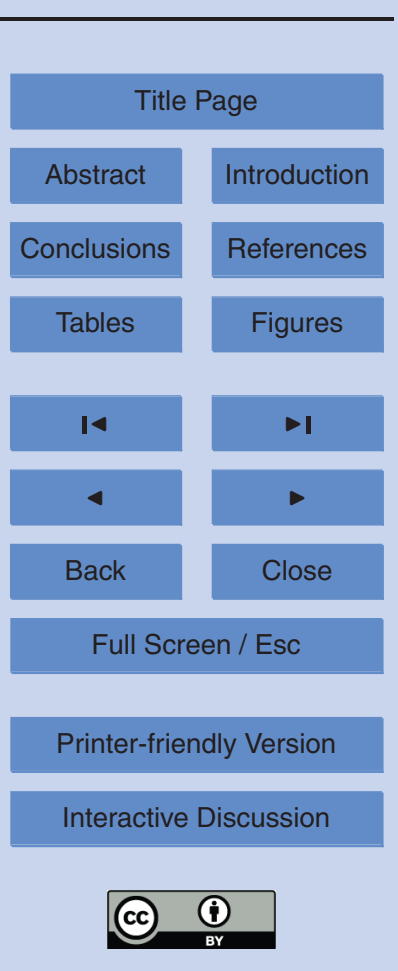


of interest for a spatial characterisation of the permafrost body. Of less than $8 \mathrm{~m}$ the vertical extent of the permafrost body at this site was quite low (cf. Fig. 7). In this case the applied electrode spacing of $2 \mathrm{~m}$ was capable of providing reliable results in detecting the permafrost base as shown by forward modelling (Fig. 4). Interpretation of 5 the vertical extent of resistive structures posed a further challenge, as it is a function of the chosen array type, applied electrode spacing as well as the dimension size and resistivity contrast to the matrix. Results are more reliable for small structures and comparably low resistivity contrasts. Reliability on the thickness of structures decreased the closer the lower boundary of resistive structures was to the penetration depth of certain 10 ERT setups (cf. Fig. 4). Application of the depth of investigation (DOI) index method (Marescot et al., 2003; Barker, 1989) on quasi-3D datasets would be a further step for verifying the quality of measurements and for preventing misinterpretations of inversion results, as well as promoting reliability of resistivity values.

Another compromise for quasi-3D applications is the choice of array type - robust15 ness against resolution power - an important question at sites with often demanding electrode coupling. Results presented in this study showed that - in consideration of the applied electrode spacing - all arrays compared (Wenner, Wenner-Schlumberger, dipole-dipole) were capable of detecting small scale resistivity variability in the subsurface (cf. Fig. 3 and 5) with mostly better results for the double dipole array and negligible differences between Wenner and Wenner-Schlumberger arrays. In particular, the reproduction of boundary conditions was favourable for the double-dipole array. Even though the sharp contrasts given by the geocryologic model between high resistive bodies and the low resistive matrix could be criticised as unlikely for natural permafrost conditions, results from synthetic modelling were confirmed by the field study in the Val Susauna (Fig. 7). The transition zone between permafrost and the matrix was less sharp for the Wenner than to the double dipole array. In contrast, no significant differences were found in the ability of the applied setups to detect the top of the modelled structures (Figs. 4 and 7). A sharp transition from active layer to permafrost body was detected by all arrays, for both the synthetic model (Fig. 4) and the site study (Fig. 7).

\section{Optimisation of quasi-3D ERI for permafrost studies}

D. Schwindt and C. Kneisel

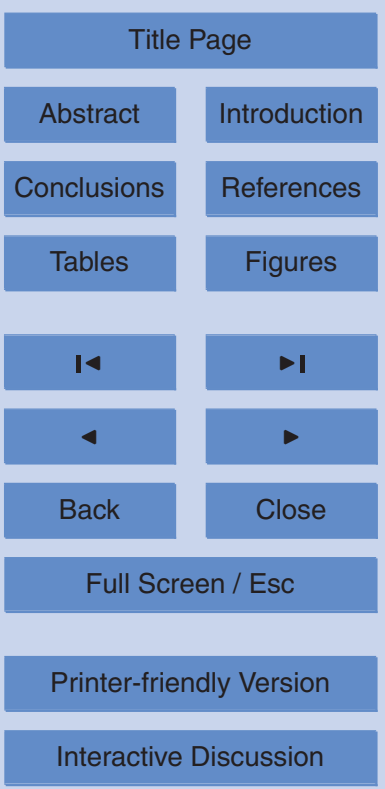


Results from synthetic modelling (Fig. 4) showed a more distinct transition zone for the double dipole array for setups with 2 and $3 \mathrm{~m}$ electrode spacing. This effect was controlled by the higher resistivity gradient for the inversion results of the double dipole arrays between matrix and resistive bodies. Nonetheless, site characteristics should 5 always be considered when selecting array type. Due to its higher error-proneness the double dipole array is not always an adequate array type at sites with poor electrode coupling. Merging measurements using various array types with different preferences (robustness, vertical/horizontal resolution) into one dataset might pose an interesting possibility for some field sites, as presented for the case study above.

10 The reliability of resistivity values was detected as the biggest drawback for quasi3D imaging. Comparison of default and inverted resistivity values showed distinct divergences. Results varied between underestimation and, in some cases, exponential overestimation of maximum values. These results confirmed the conclusion of Marescot et al. (2003), based on DOI calculations for 2D arrays, that the values within 15 the high resistive zones cannot be determined accurately. Relations between resistivity of $2 \mathrm{D}$ profiles in comparison to values of quasi-3D inversions were presented for the permafrost site in the Val Susauna (Fig. 8). Results underlined the conclusion from synthetic modelling, that a quantitative interpretation of subsurface characteristics (permafrost conditions, ice content and temperature) from inversion results is not always appropriate. Differences arose not only between applied array types but also between measurements in the $x$ - and y-directions (Fig. 7). The effect of geometric layout of the survey lines influencing measurement results has been described by Hauck and Vonder Mühll (2003b) for 2D-ERT measurements on an ice-cored moraine. These results were confirmed for the talus slope of the Val Susauna.

25 Besides grid setup the correct alignment of inversion parameters is of fundamental importance for achieving interpretable quasi-3D images. Special focus in this study was placed on the convergence criterion, trying to extend the investigations of Hauck and Vonder Mühll (2003b) for quasi-3D measurements. Results provided in Fig. 6 underline the importance of choosing the correct iteration. While the increase of maximum

\section{Optimisation of quasi-3D ERI for permafrost studies}

D. Schwindt and C. Kneisel

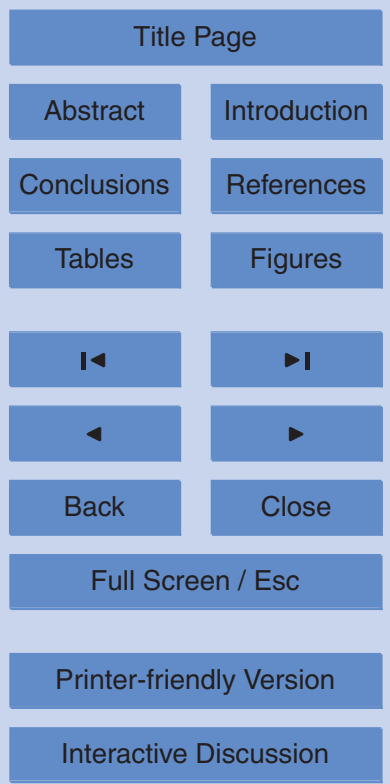


resistivities under a prolonged inversion process was less pronounced for the quasi3D case compared to results of Hauck and Vonder Mühll (2003b) a distinct impact was proved for shallow layers. Inversion artefacts arose above high resistivity structures that could result in uncertainties and misinterpretations. The case study in the

5 Val Susauna (Fig. 7), proved to be an interesting example where the top three layers showed a small area with higher resistivities resulting from variations in surface substrate (dolomitic material in contrast to a consistent humus/moss cover). A prolonged inversion process would have resulted in banding effects - as shown for synthetic data in Fig. 6 - above the high resistive permafrost body. In return small scale surface 10 variability could be superimposed by scattered artefacts in shallow depth layers. Likewise, banding effects above resistive bodies could result in misinterpretations of active layer thickness. Scattered high resistive structures in the shallow subsurface may also be interpreted as a result of bad electrode coupling and unfavourable contact resistances. Consequently, banding effects could lead to applying higher damping factors on the inversion algorithm, influencing resistivity values and resistivity contrasts between anomalies and background material (cf. Hauck and Vonder Mühll, 2003b). The effect of applying different damping factors on a quasi-3D dataset from a permafrost site in the Murtèl glacier forefield was analysed by Rödder and Kneisel (2011).

\section{Conclusions}

20 Delineation of the spatial permafrost distribution in mountain environments enables linkages to be made between site specific surface and subsurface characteristics and enhances the explanatory power of geophysical studies regarding a variety of problems such as the thermal regime/energy balance as well as geotechnical problems such as alpine infrastructure as well as possible geohazards, especially in the con25 text of anticipated global warming and subsequent permafrost degradation. Results from forward modelling and field measurements demonstrate the potential of quasi$3 \mathrm{D}$ resistivity imaging for permafrost studies in mountain environments. Based on

\section{Optimisation of quasi-3D ERI for permafrost studies}

D. Schwindt and C. Kneisel

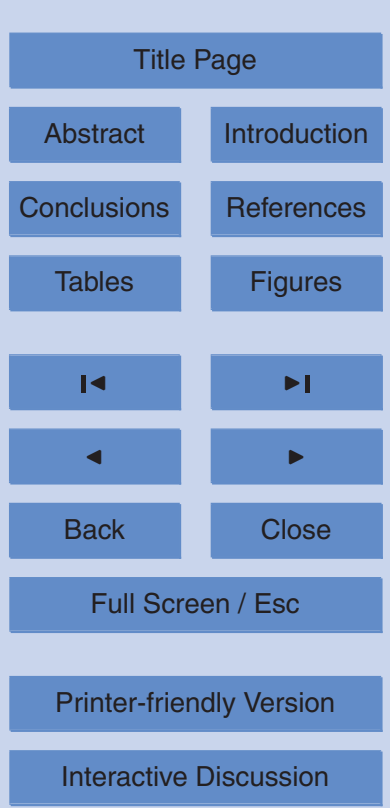


synthetic modelling and site investigations the following conclusions on application, inversion and interpretation of quasi-3D resistivity imaging can be drawn:

- Quasi-3D grids should always consist of measurements in $\mathrm{x}$ - and y-direction to achieve reliable data and to detect small-scale heterogeneity in the subsurface. Using parallel lines only the line spacing should not exceed the electrode spacing.

- The double dipole setups provide best results regarding lateral resolution, permitting the application of larger electrode and line spacings, but are more prone to errors. In contrast the more robust Wenner/Wenner-Schlumberger arrays have a larger penetration depth and advantages in resolving the base of resistive structures. As for the 2D-case array type should be chosen with view on surface characteristics. Measurement and combined inversion of different array types can provide superior results.

- Choice of electrode spacing poses a trade-off between horizontal resolution, detection of active layer thickness, and penetration depth, i.e. detection of the permafrost base. Best results are provided by grid setups using $2 \mathrm{~m}$ and $3 \mathrm{~m}$ spacings. Electrode spacings $>3 \mathrm{~m}$ are not recommended due to distinct disadvantages regarding the horizontal resolution but might be necessary in some cases for exploring greater depth.

- The maximum line spacing that provides reliable results is a function of the electrode spacing. While quadruple line spacing provides good results using $2 \mathrm{~m}$ electrode spacing, data quality diminishes as the electrode spacing enlarges. As a rule of thumb, the smaller the electrode spacing and the higher the number of perpendicular tie lines, the more the spacing between adjacent lines can be enlarged.

- In the case of trading efficiency of measurement against model resolution, the application of $t$ riple electrode spacing between adjacent profiles can be recommended for setups using electrode spacings $\leq 3 \mathrm{~m}$. In this case reducing 3406

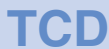

$5,3383-3421,2011$

\section{Optimisation of quasi-3D ERI for permafrost studies}

D. Schwindt and

C. Kneisel

Title Page

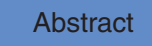

Introduction

Conclusions

Tables

References

Figures

14

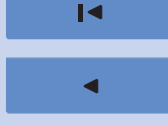

$\rightarrow$

Back

Close

Full Screen / Esc

Printer-friendly Version

Interactive Discussion 
the number of perpendicular tie lines by half, i.e. doubling the spacing of tie lines, provides reliable data.

- Choice of iteration should be based not only on the RMS error but also on the evolution of resistivity values, resistivity contrast and on the appearance of artefacts. A prolonged inversion process affects the resulting resistivity values and contrasts but also tends to produce noise and inversion artefacts in shallow layers especially above resistive structures. This may lead to reduced interpretability and misinterpretations of the quasi-3D data.

- Interpretability of the vertical extent of resistive structures is limited for all grid setups. The smaller the vertical extent of the permafrost body and the lower the resistivity gradient, the better the delineation of the permafrost base. Vertical extent is usually overestimated for large structures and high resistivity gradients.

- An absolute interpretation of resistivity values for deducing permafrost properties (ice/liquid water content, permafrost temperature) using quasi-3D ERT-data is limited. Measured and modelled resistivity values strongly depend on line orientation, electrode spacing and array type and are influenced by the site-specific geomorphological setting. Additional information on the subsurface (e.g. SRT, temperature logging) could enhance the interpretability of quasi-3D resistivity measurements.

- Use of the back-and-forth interpretation procedure is valuable for optimising the quasi-3D application for specific objectives and sites as well as for enhancing the interpretability of observed data.

Quasi-3D imaging has proven to be a valuable tool for detecting and investigating permafrost in mountain environments. In particular, the possibility to delineate the often small-scale permafrost heterogeneity and spatial variability of active layer thickness is improved compared to single 2D measurements, which provides an enhanced

\section{Optimisation of quasi-3D ERI for permafrost studies}

D. Schwindt and

C. Kneisel

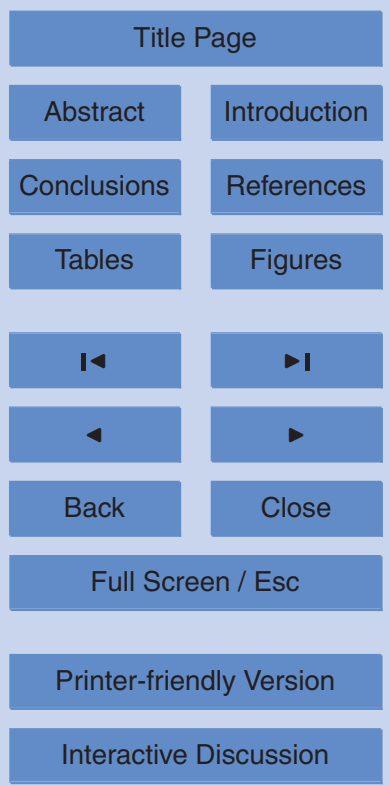


potential for aligning permafrost distribution with site-specific surface properties and morphological setting.

Acknowledgements. For assistance during field work the authors would like to thank Julie Kästl and Nils Roth. We gratefully acknowledge Tobias Rödder for help during data acquisition, com-

5 ments on the manuscript and for the various valuable discussions. Special thanks to Anna Gray for proofreading of the manuscript. This study was supported by a personal grant from the Bayerische Graduiertenförderung nach dem Bayerischen Eliteförderungsgesetzt (BayEFG). This publication was funded by the German Research Foundation (DFG) and the University of Wuerzburg in the funding programme Open Access Publishing.

\section{References}

Alvarez-Uria, P. and Körner, C.: Low temperature limits of root growth in deciduous and evergreen temperate tree species, Func. Ecol., 21, 211-218, 2007.

Barker, R. D.: Depth of investigation of collinar symmetrical four-electrode arrays, Geophysics, 54, 1031-1037, 1989.

15 Bentley, L., R. and Gharibi, M.: Two- and three-dimensional electrical resistivity imaging at a heterogeneous remediation site, Geophysics, 69, 674-680, 2004.

Bichler, A., Bobrowsky, P., Best, M., Douma, M., Hunter, J., Calvert, T., and Burns, R.: Threedimensional mapping of a landslide using a multi-geophysical approach: The quesnel forks landslide, Landslides, 1, 29-40, 2004.

20 Chambers, J. E., Wilkinson, P. B., Weller, A. L., Meldrum, P. I., Ogilvy, R. D., and Caunt, S.: Mineshaft imaging using surface and crosshole 3D electrical resistivity tomography: A case history from the east pennine coalfield, UK, J. Appl. Geophys., 62, 324-337, 2007.

Dahlin, T. and Loke, M. H.: quasi-3D resistivity imaging - mapping of three dimensional structures using two dimensional dc resistivity techniques, 3rd Meeting Environmental and Engineering Geophysics, Aarhaus, Denmark, 1997,

Dahlin, T., Bernstone, C., and Loke, M. H.: A 3D resistivity investigation of a contaminated site at lernacken, sweden, Geophysics, 67, 1692-1700, 2002.

Delaloye, R., Reynard, E., Lambiel, C., Marescot, L., and Monnet, R.: Thermal anomaly in a cold scree slope (creux du van, switzerland), 8th International Conference on Permafrost,

\section{Optimisation of quasi-3D ERI for permafrost studies}

D. Schwindt and C. Kneisel

Title Page

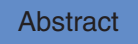

Introduction

Conclusions References

Tables Figures
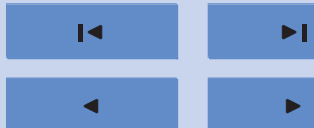

Back

Close

Full Screen / Esc

Printer-friendly Version

Interactive Discussion 
Dey, A. and Morrison, H. F.: Resistivity modelling for arbitrarily shaped two-dimensional structures, Geophys. Prospect., 27, 106-136, 1979.

Farquharson, C. G.: Constructing piecewise-constant models in multidimensional minimumstructure inversions, Geophysics, 73, 1-9, 2008.

5 Fischanger, F., Morelli, G., LaBrecque, D. J., and Occhi, M.: Monitoring resins injection with 3D electrical resistivity tomography (ert) using surface and multi-borehole electrode arrays, SAGEEP 20th Annual meeting, Denver, 2007,

Fortier, R., LeBlanc, A.-M., Allard, M., Buteau, S., and Calmels, F.: Internal structure and conditions of permafrost mounds at umiujaq in nunavik, canada, inferred from field investigation

10 and electrical resistivity tomography, Can. J. Earth Sci., 45, 367-387, 2008.

Friedel, S.: Resolution, stability and efficiency of resistivity tomography estimated from a generalized inverse approach, Geophys. J. Int., 153, 305-316, 2003.

Friedel, S., Thielen, A., and Springman, S. M.: Investigation of a slope endangered by rainfallinduced landslides using 3D resistivity tomography and geotechnical testing, J. Appl. Geophys., 60, 100-114, 2006.

Garré, S., Javaux, M., Vanderborght, J., Pages, L., and Vereecken, H.: Three-dimensional electrical resistivity tomography to monitor root zone water dynamics, Vadose Zone J., 10, 412-424, 2011.

Gharibi, M. and Bentley, L. R.: Resolution of 3D electrical resistivity images from inversions of 2D orthogonal lines, J. Environ. Eng. Geophys., 10, 339-349, 2005.

Harris, S. A. and Pedersen, D. E.: Thermal regimes beneath coarse blocky materials, Permafr. Periglac. Proc., 9, 107-120, 1998.

Hauck, C.: Frozen ground monitoring using dc resistivity tomography, Geophys. Res. Lett., 29, 2016, 2002.

Hauck, C. and Vonder Mühll, D.: Evaluation of geophyical techniques for aplication in mountain permafrost studies, Zeitschr. Geomorph., 132, 161-190, $2003 a$.

Hauck, C. and Vonder Mühll, D.: Inversion and interpretation of two-dimensional geoelectrical measurements for detecting permafrost in mountain regions, Permafr. Periglac. Proc., 14, 305-318, 2003b.

so Hilbich, C., Marescot, L., Hauck, C., Loke, M. H., and Mausbacher, R.: Applicability of electrical resistivity tomography monitoring to coarse blocky and ice-rich permafrost landforms, Permafr. Periglac. Proc., 20, 269-284, 2009.

Kneisel, C.: Sporadic and discontinous mountain permafrost occurrence in the upper engadine,

\section{Optimisation of quasi-3D ERI for permafrost studies}

D. Schwindt and

C. Kneisel

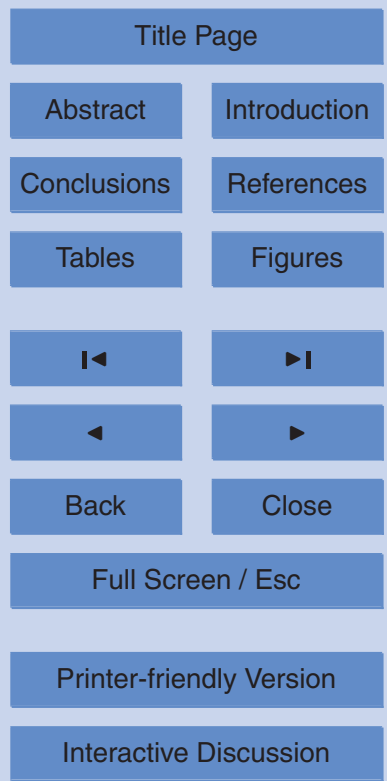


eastern swiss alps, Permafrost, Vols. 1 and 2, edited by: Phillips, M., Springman, S. M., and Arenson, L. U., 561-566, 2003.

Kneisel, C.: New insights into mountain permafrost occurrence and characteristics in glacier forefields at high altitude through the application of 2D resistivity imaging, Permafr. Periglac.

5 Proc., 15, 221-227, 2004.

Kneisel, C. and Schwindt, D.: Geophysical mapping of isolated permafrost lenses at a sporadic permafrost site at low altitude in the swiss alps, 9th International Conference on Permafrost, Fairbanks, Alaska, 2008.

Kneisel, C., Hauck, C., and Vonder Mühll, D.: Permafrost below the timberline confirmed and characterized by geoelectrical resistivity measurements, bever valley, eastern swiss alps, Permafr. Periglac. Proc., 11, 295-304, 2000.

Kneisel, C., Hauck, C., Fortier, R., and Moorman, B.: Advances in geophysical methods for permafrost investigations, Permafr. Periglac. Proc., 19, 157-178, 2008.

Krautblatter, M.: Rock permafrost geophysics and its explanatory power for permafrost-induced 15 rockfalls and rock creep: A perspective, 9th International Conference on Permafrost, Fairbanks, Alaska, 2008.

Krautblatter, M. and Hauck, C.: Electrical resistivity tomography monitoring of permafrost in solid rock walls, J. Geophys. Res.-Earth Surf., 112, F02S20, doi:10.1029/2006JF000546, 2007

20 Krautblatter, M. and Verleysdonk, S.: Rock wall permafrost monitoring with high-resolution 2Dert: Lessons learnt from error estimates and a comparison of wenner, schlumberger, gradient and dipole-type arrays, Geophys. Res. Abstr., 10, 2008.

Krautblatter, M. T., Verleysdonk, S., Flores-Orozco, A., and Kemna, A.: Temperature-calibrated imaging of seasonal changes in permafrost rock walls by quantitative electrical resistivity tomography (zugspitze, german/austrian alps), J. Geophys. Res., 115, F02O03, doi:10.1029/2008JF001209, 2010.

Loke, M. H.: The inversion of two-dimensional apparent resistivity data, University of Birmingham, University of Birmingham, Birmingham (UK), 1994.

Loke, M. H.: Res2Dmod ver. 3.01 - rapid 2D resistivity forward modelling using the finitedifference and finite-element methods, 2002.

Loke, M. H.: Tutorial: 2D and 3D electrical imaging surveys, http://www.geoelectrical.com/ downloads.php, 2010.

Loke, M. H. and Barker, R. D.: Practical techniques for 3D resistivity surveys and data inversion,

\section{Optimisation of quasi-3D ERI for permafrost studies}

D. Schwindt and C. Kneisel

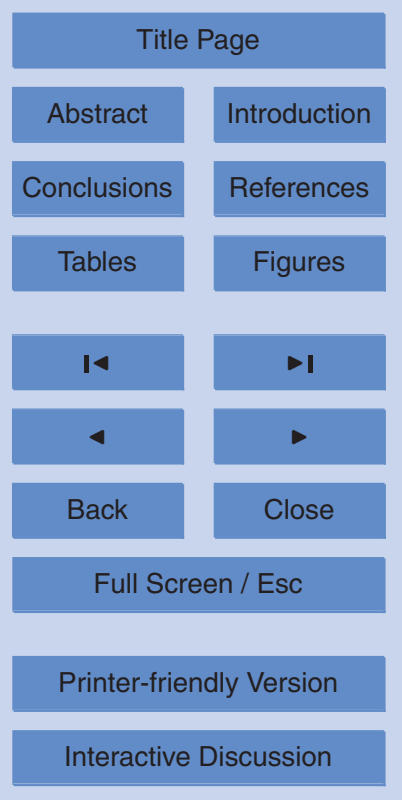


Geophys. Prospect., 44, 499-523, 1996.

Loke, M. H. and Dahlin, T.: A comparison of the gauss-newton and quasi-newton methods in resistivity imaging inversion, J. Appl. Geophys., 49, 149-162, 2002.

Loke, M. H., Acworth, I., and Dahlin, T.: A comparison of smooth and blocky inversion methods in 2D electrical imaging surveys, Explor. Geophys., 34, 182-187, 2003.

Marescot, L., Loke, M. H., Chapellier, D., Delaloye, R., Lambiel, C., and Reynard, E.: Assessing reliability of $2 \mathrm{D}$ resistivity imaging in mountain permafrost studies using the depth of investigation index method, Near Surf. Geophys., 1, 57-67, 2003.

Morelli, A., Morelli, G., Chiara, P., Pacchini, A., and Fischanger, F.: Characterization of complex archaeological sites using 3D electrical resistivity tomography, SAGEEP 17th Annual meeting, Colorado Springs, 2004,

Oldenburg, D. W. and Li, Y.: Estimating depth of investigation in dc resistivity and ip surveys, Geophysics, 64, 403-416, 1999.

Papadopoulos, N. G., Tsourlos, P., Tsokas, G. N., and Sarris, A.: Two-dimensional and three15 dimensional resistivity imaging in archaeological site investigation, Archaeol. Prospect., 13, 163-181, 2006.

Papadopoulos, N. G., Tsourlos, P., Tsokas, G. N., and Sarris, A.: Efficient ert measuring and inversion strategies for 3D imaging of buried antiquities, Near Surf. Geophys., 5, 349-361, 2007.

20 Park, S.: Fluid migration in the vadose zone from $3 \mathrm{D}$ inversion of resistivity monitoring data, Geophysics, 63, 41-51, 1998.

Rödder, T. and Kneisel, C.: Permafrost mapping using quasi-3D resistivity imaging, murtèl, swiss alps, Near Surf. Geophys., 9, doi:10.3997/1873-0604.2011029, 2011.

Rucker, D. F., Levitt, M. T., and Greenwood, W. J.: Three-dimensional electrical resistivity model of a nuclear waste disposal site, J. Appl. Geophys., 69, 150-164, 2009.

Scales, J. A. and Snieder, R.: The anatomy of inverse problems, Geophysics, 65, 1708-1710, 2000.

Schwindt, D.: Geophysikalische kartierung und bodenkundliche charakterisierung eines subalpinen standorts mit permafrost, in: Department of Physical Geography, University of Trier, $30 \quad$ Trier, 140, unpublished 2007.

Schwindt, D. and Kneisel, C.: quasi-3D resistivity imaging - results from geophysical mapping and forward modeling, Geophys. Res. Abstr., 11, 2009.

Schwindt, D. and Kneisel, C.: Temporal permafrost variability at three subalpine talus slopes in

\section{Optimisation of quasi-3D ERI for permafrost studies}

D. Schwindt and C. Kneisel

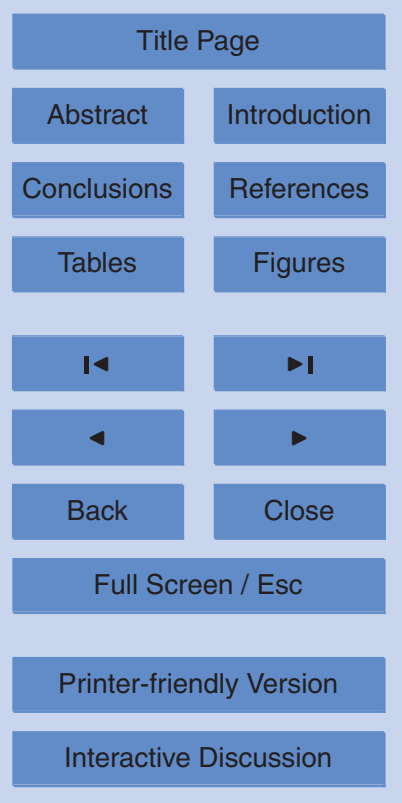


the swiss alps, by geoelectrical monitoring and supplemental methods 3rd European Conference on Permafrost (EUCOP III), Svalbard, Norway, 2010,

Scott, W. J., Sellmann, P. V., and Hunter, J. A.: Geophysics in the study of permafrost, in: Geotechnical and environmental geophysics, Vol. 1 Review and Tutorial, edited by: Ward, S. $5 \quad$ H., Society of Exploration, 355-384, 1990.

Silvester, P. P. and Ferrari, R. L.: Finite elements for electrical engineers, 3 ed., Cambridge University Press, Cambridge, 516 pp., 1996.

Soupios, P., Papadopoulos, I., Kouli, M., Georgaki, I., Vallianatos, F., and Kokkinou, E.: Investigation of waste disposal areas using electrical methods: A case study from chania, Crete, Greece, Environ. Geol., 51, 1249-1261, 2007.

Wakonigg, H.: Unterkühlte schutthalden, in: Beiträge zur permafrostforschung in österreich, Arbeiten aus dem Institut für Geographie der Karl-Franzens-Universität Graz, 209-223, 1996.

\section{Optimisation of quasi-3D ERI for permafrost studies}

D. Schwindt and

C. Kneisel

Title Page

Abstract Introduction

Conclusions References

Tables Figures

14

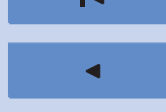

Back

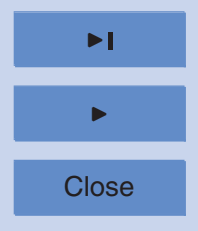

Full Screen / Esc

Printer-friendly Version

Interactive Discussion 
Table 1. Dimension parameters of the grid setups for double, triple and quadruple line spacing, 2, 3 and $5 \mathrm{~m}$ electrode spacing and the array types Wenner, Wenner-Schlumberger and dipoledipole.

\begin{tabular}{|c|c|c|c|c|c|c|c|c|}
\hline & & \multirow[b]{2}{*}{ Grid size $(m)$} & \multicolumn{2}{|c|}{ \# of Lines } & \multirow[t]{2}{*}{ \# of Electrodes } & \multicolumn{3}{|c|}{ \# of Datum Points } \\
\hline & & & $x$ & $\mathrm{y}$ & & Wenner & Wenner-Schlumberger & Dipole-Dipole \\
\hline \multirow{3}{*}{ Double } & $2 \mathrm{~m}$ & $168 \times 72$ & 17 & 42 & 2124 & 24500 & 30320 & 37400 \\
\hline & $3 m$ & $168 \times 105$ & 17 & 28 & 1620 & 14112 & 18672 & 24072 \\
\hline & $5 \mathrm{~m}$ & $175 \times 175$ & 17 & 18 & 1260 & 6930 & 10080 & 14280 \\
\hline \multirow{3}{*}{ Triple } & $2 \mathrm{~m}$ & $168 \times 72$ & 11 & 28 & 1404 & 16016 & 19856 & 24536 \\
\hline & $3 m$ & $168 \times 105$ & 12 & 19 & 1116 & 9810 & 12960 & 16680 \\
\hline & $5 \mathrm{~m}$ & $175 \times 175$ & 12 & 12 & 864 & 4752 & 6912 & 9792 \\
\hline \multirow{3}{*}{ Quadruple } & $2 \mathrm{~m}$ & $168 \times 72$ & 9 & 21 & 1080 & 12726 & 15696 & 19296 \\
\hline & $3 m$ & $168 \times 105$ & 9 & 15 & 864 & 7506 & 9936 & 12816 \\
\hline & $5 \mathrm{~m}$ & $175 \times 175$ & 8 & 9 & 612 & 3366 & 4896 & 6936 \\
\hline
\end{tabular}

\section{Optimisation of quasi-3D ERI for permafrost studies}

D. Schwindt and
C. Kneisel

\section{Title Page}

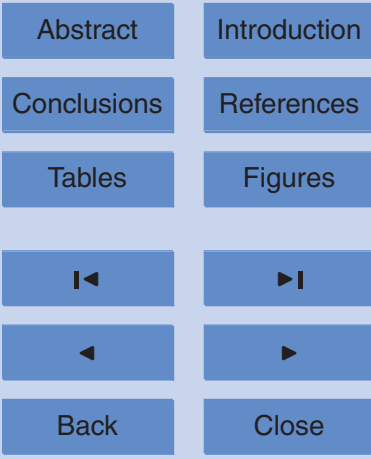

Full Screen / Esc

Printer-friendly Version

Interactive Discussion 


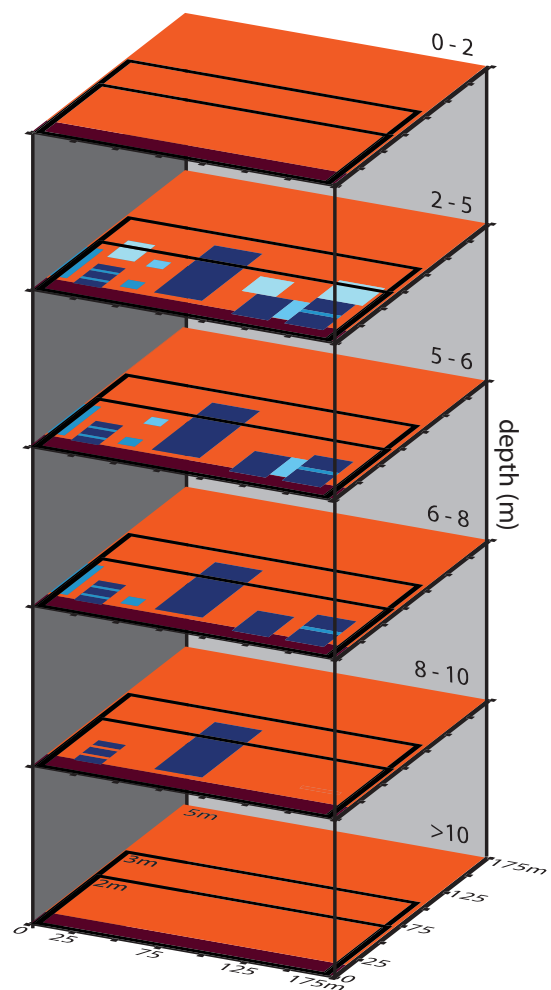

Resistivity in kOhm.m

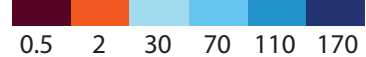

Fig. 1. Geocryologic model of subsurface resistivity distribution for forward modelling. Dimension size is variable according to the applied electrode spacing ( $5 \mathrm{~m}$ electrode spacing covers the whole model, grid size for $2 \mathrm{~m}$ and $3 \mathrm{~m}$ electrode spacing is given by the black squares).

\section{TCD}

$5,3383-3421,2011$

\section{Optimisation of quasi-3D ERI for permafrost studies}

D. Schwindt and
C. Kneisel

Title Page

\section{Abstract}

Conclusions

\section{Tables}

14

4

Back
Introduction

References

Figures

$\rightarrow$

$>$

Close
Full Screen / Esc

Printer-friendly Version

Interactive Discussion 


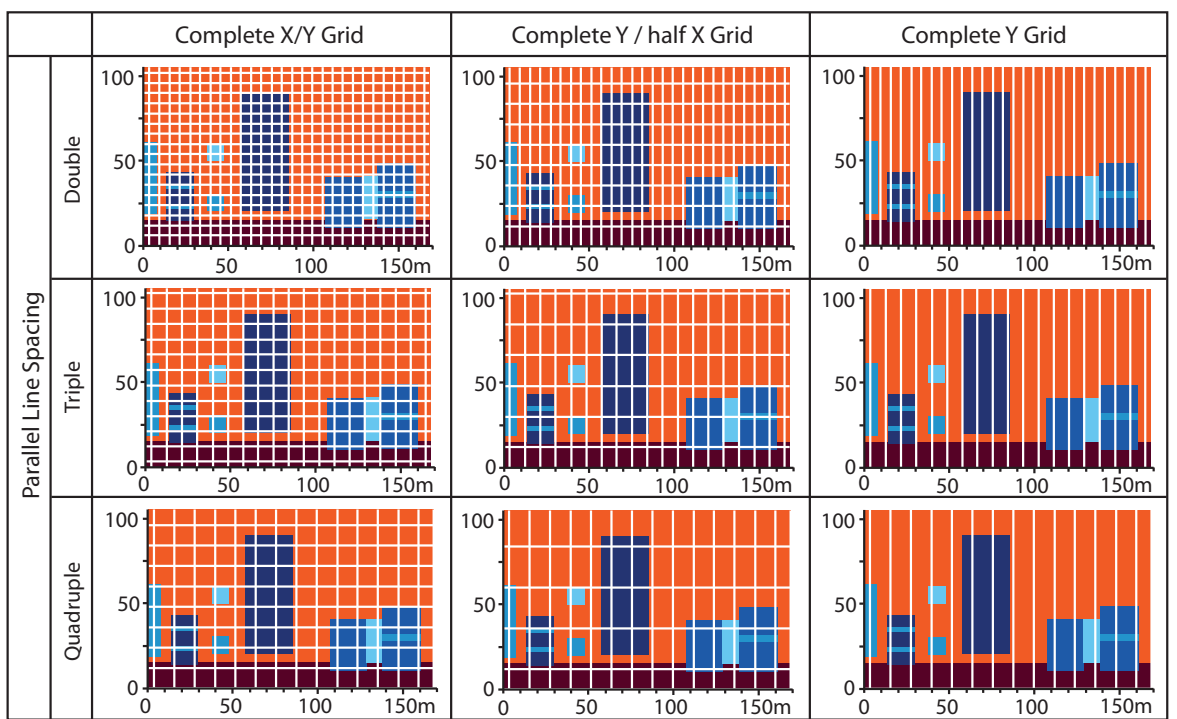

Fig. 2. Modelled grid setups, exemplified using an electrode spacing of $2 \mathrm{~m}$. Parallel line spacing is based on the applied electrode spacing with double, triple and quadruple value. For testing the influence of minimising the number of arrays included in each model distance between adjacent arrays is enlarged, using double, triple and quadruple electrode spacing. To test the importance of perpendicular tie lines, synthetic models were created with a complete $\mathrm{x} / \mathrm{y}$-grid, with a reduced number of lines in $\mathrm{x}$-direction and without tie lines.

\section{Optimisation of quasi-3D ERI for permafrost studies}

D. Schwindt and

C. Kneisel

Title Page

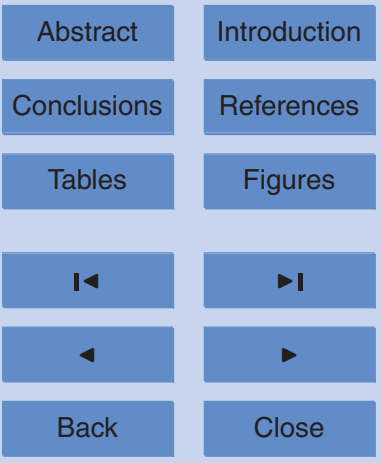

Full Screen / Esc

Printer-friendly Version

Interactive Discussion 


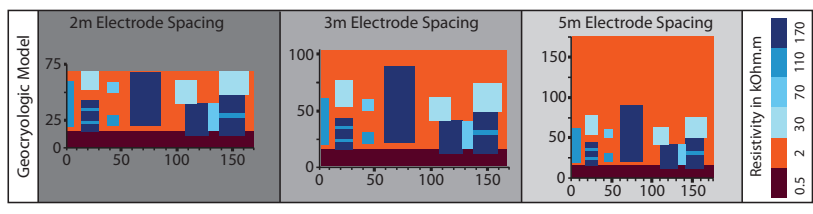

TCD

$5,3383-3421,2011$

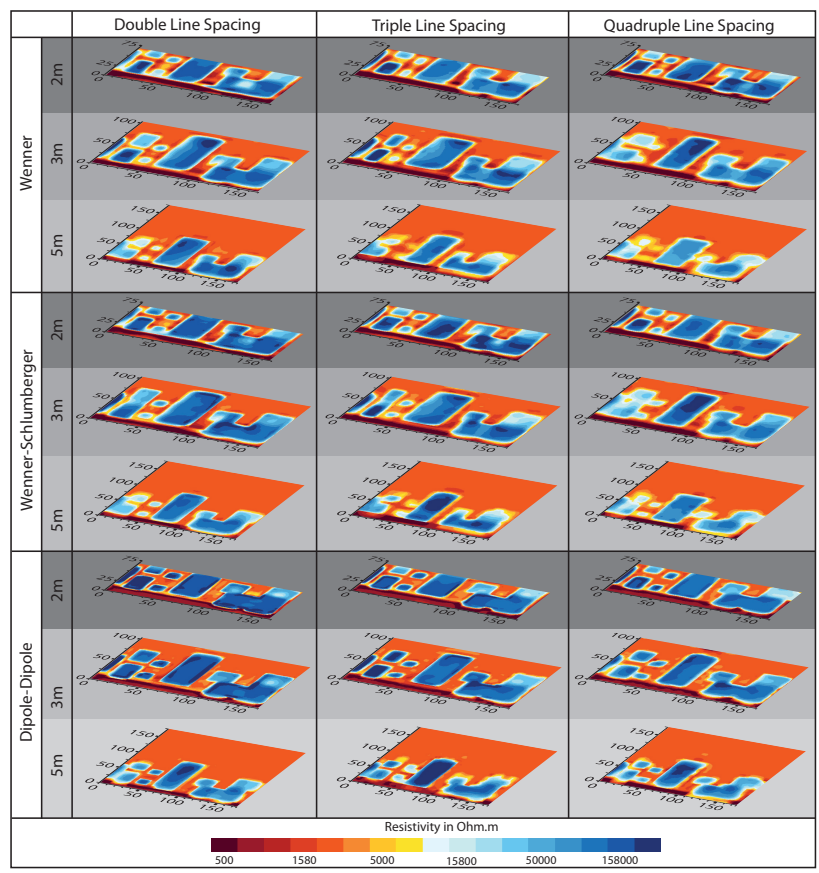

\section{Optimisation of quasi-3D ERI for permafrost studies}

D. Schwindt and

C. Kneisel

Title Page

Abstract

Conclusions

Tables

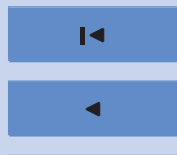

Back
Introduction

References

Figures

I

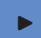

Close

Fig. 3. Lateral resolution of different setups in comparison to the geocryologic model. Presented are the depth slices between 3 and $4 \mathrm{~m}$ depths (grid setups using 2 and $3 \mathrm{~m}$ unit electrode spacing) and $3.5-5 \mathrm{~m}$ depths (5 $\mathrm{m}$ unit electrode spacing).

Full Screen / Esc

Printer-friendly Version

Interactive Discussion 


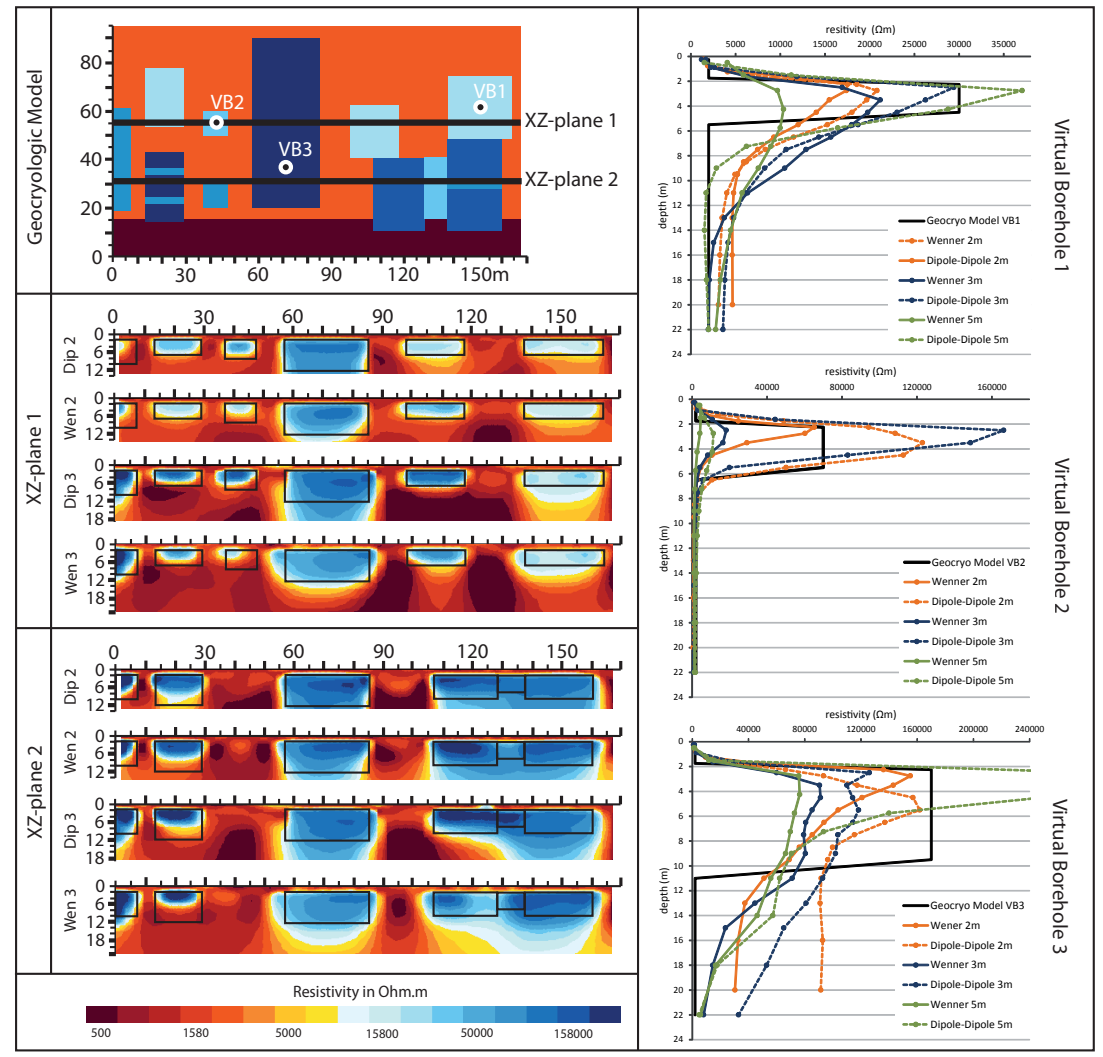

Fig. 4. Vertical model resolution, i.e. detection of the top and base of resistive structures. 2D slices in $\mathrm{x} / \mathrm{z}$-direction (location is marked in the geocryologic model on top of the Figure) are compared for the array types Wenner and dipole-dipole ( $2 \mathrm{~m}$ and $3 \mathrm{~m}$ electrode spacing). Default dimension size of the resistive structures is given by the black rectangles. Three virtual boreholes (VB 1-3; marked by white dots) present the vertical resistivity distribution for all grid setups in comparison to default values of the geocryologic model (resistivity-scale is adjusted for each virtual borehole).

\section{TCD}

5, 3383-3421, 2011

\section{Optimisation of quasi-3D ERI for permafrost studies}

D. Schwindt and

C. Kneisel

\section{Title Page}

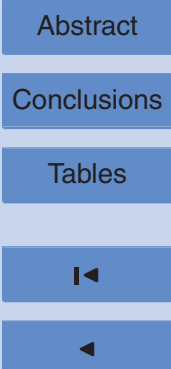

Introduction

References

Figures

- I

$\checkmark$

Back

Close

\section{Full Screen / Esc}

Printer-friendly Version

Interactive Discussion 


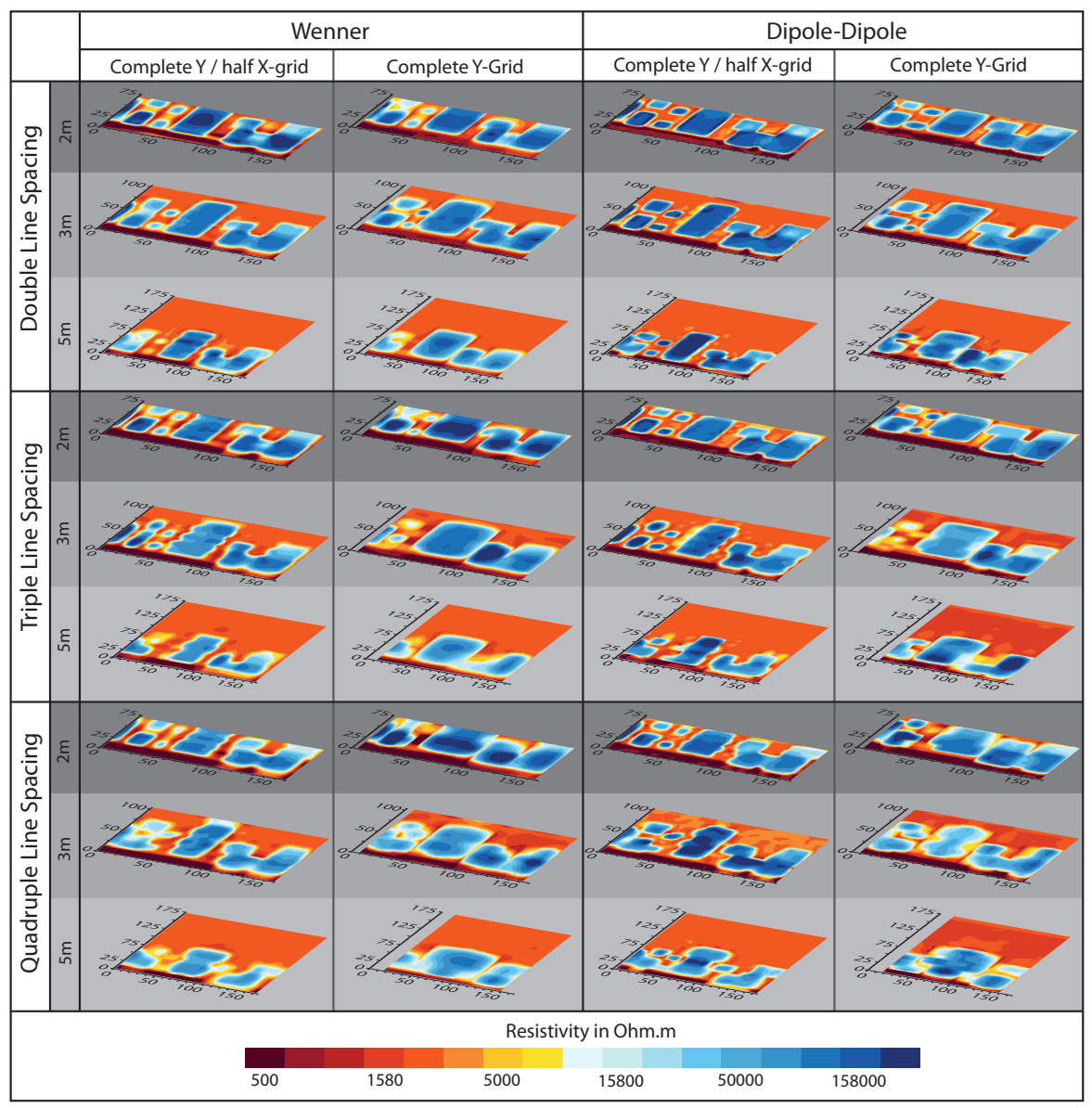

TCD

$5,3383-3421,2011$

\section{Optimisation of quasi-3D ERI for permafrost studies}

D. Schwindt and C. Kneisel

Title Page

Abstract

Conclusions

Tables

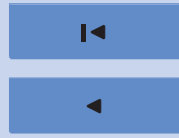

Back

Full Screen / Esc

Printer-friendly Version

Interactive Discussion
Fig. 5. Depth slices (between $3 \mathrm{~m}$ and $5 \mathrm{~m}$ depths) testing the effect of reducing the number of 2D-arrays for building up a quasi-3D model on data quality and lateral resolution.
Introduction

References

Figures

\section{$\rightarrow 1$}

$>$

Close

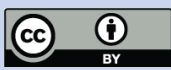



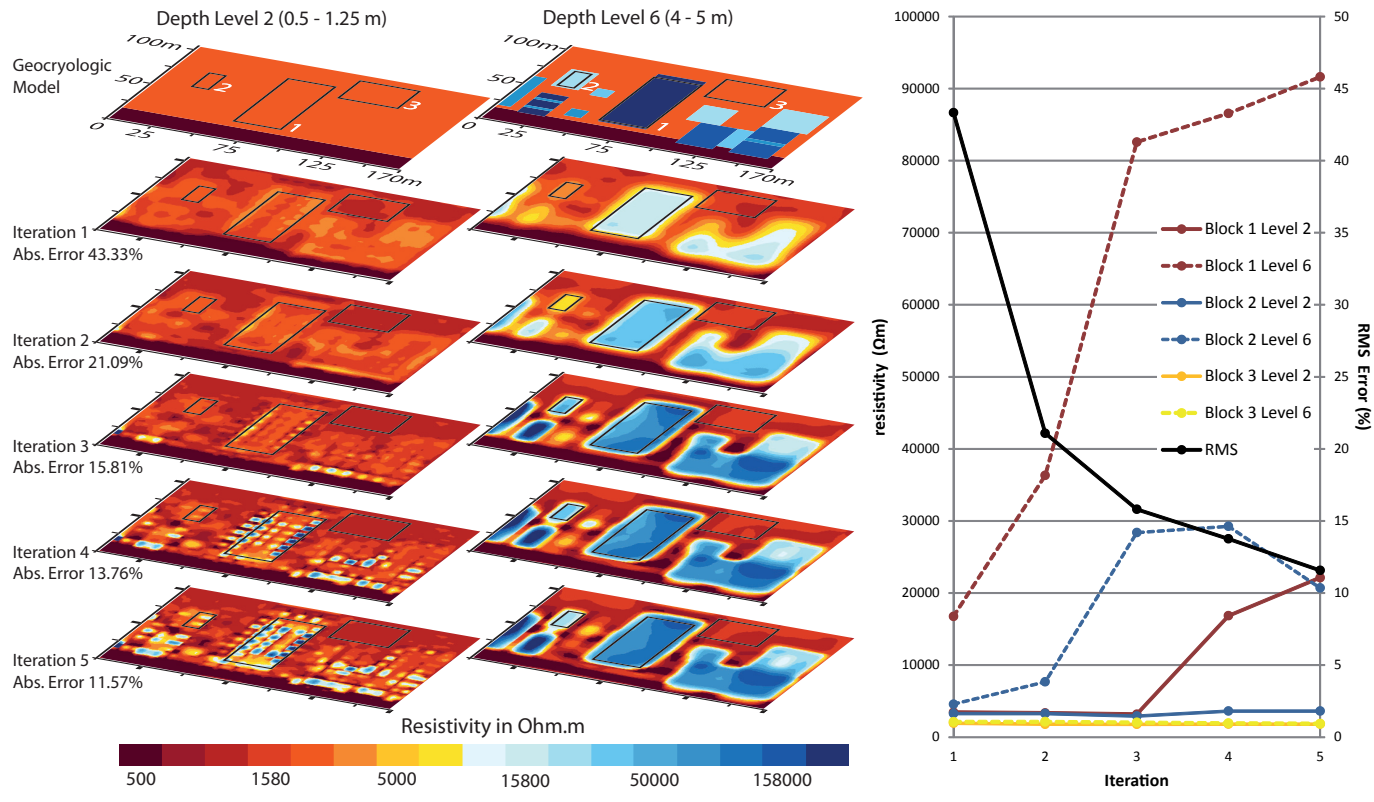

Fig. 6. Comparison of the response of the iteration process on resistivity distribution in two depth layers and the evolution of the RMS error of an exemplarily chosen quasi-3D model (Wenner array, $3 \mathrm{~m}$ electrode spacing, triple line spacing). Resistivities shown in the diagram represent averaged values for three blocks (locations are marked in the depth slices) of the depth layers $2(0.5 \mathrm{~m}-1 \mathrm{~m})$ and $6(4 \mathrm{~m}-5 \mathrm{~m})$ in comparison to the RMS error.

\section{Optimisation of quasi-3D ERI for permafrost studies}

D. Schwindt and

C. Kneisel

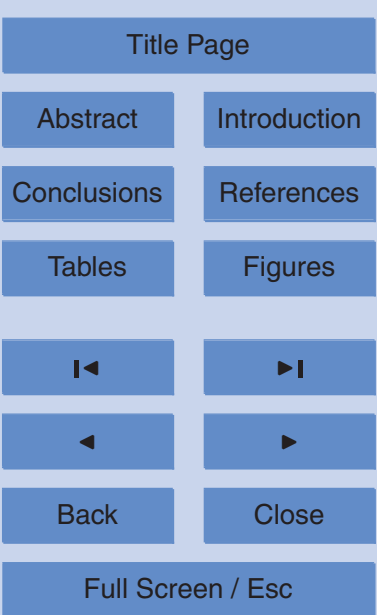

Printer-friendly Version

Interactive Discussion 

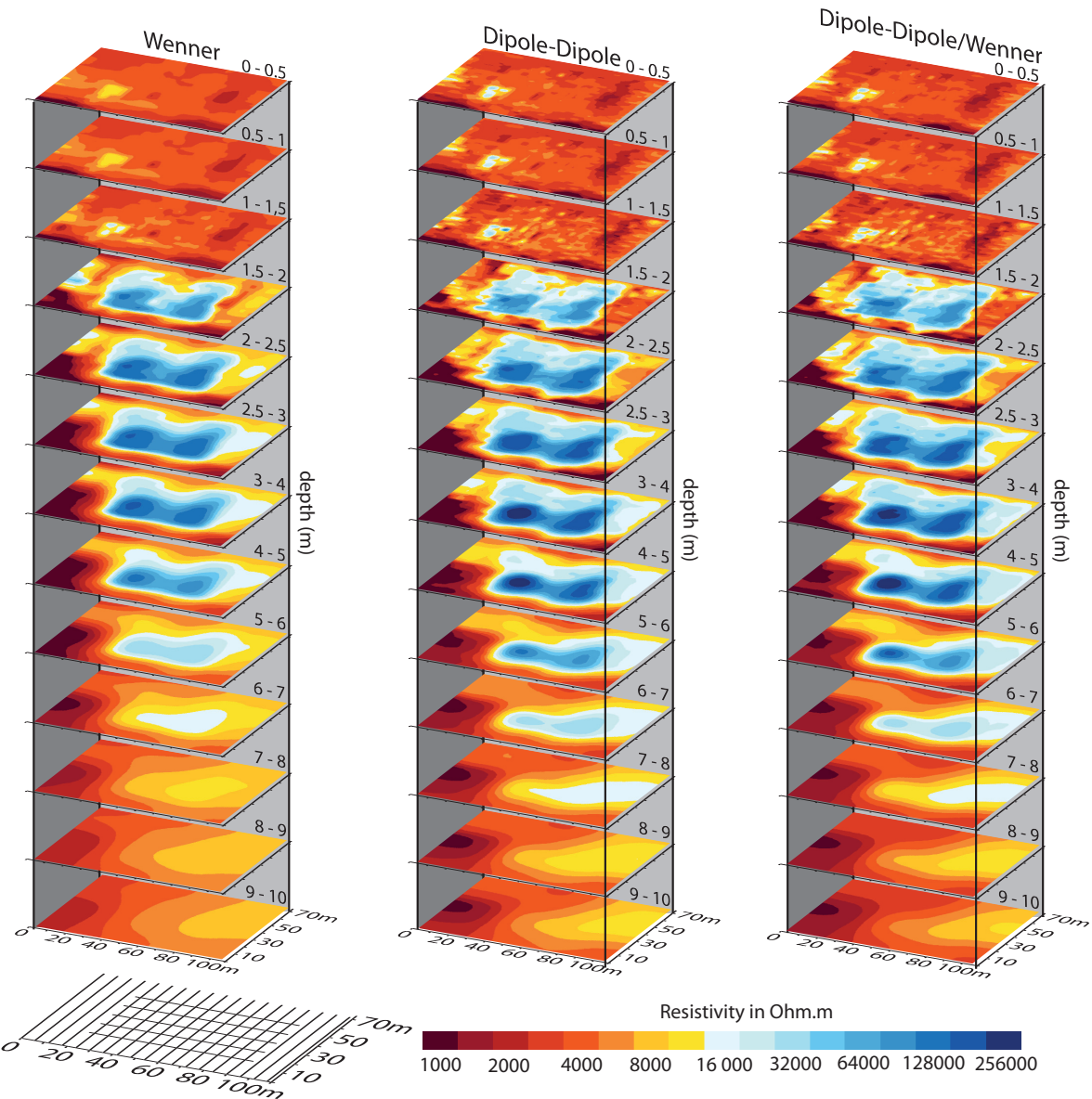

Resistivity in Ohm.m

$1000 \quad 2000 \quad 4000 \quad 8000 \quad 16000 \quad 32000 \quad 64000 \quad 128000 \quad 256000$

Fig. 7. Depth slices of the quasi-3D image measured in the Val Susauna, Upper Engadin, Swiss Alps for the array types Wenner, dipole-dipole and an inversion of a collated dataset of both arrays as well as the line arrangement for the setups.

\section{TCD}

$5,3383-3421,2011$

\section{Optimisation of quasi-3D ERI for permafrost studies}

D. Schwindt and C. Kneisel

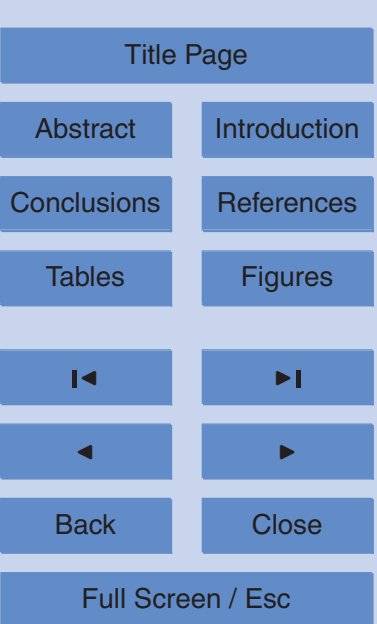

Printer-friendly Version

Interactive Discussion 


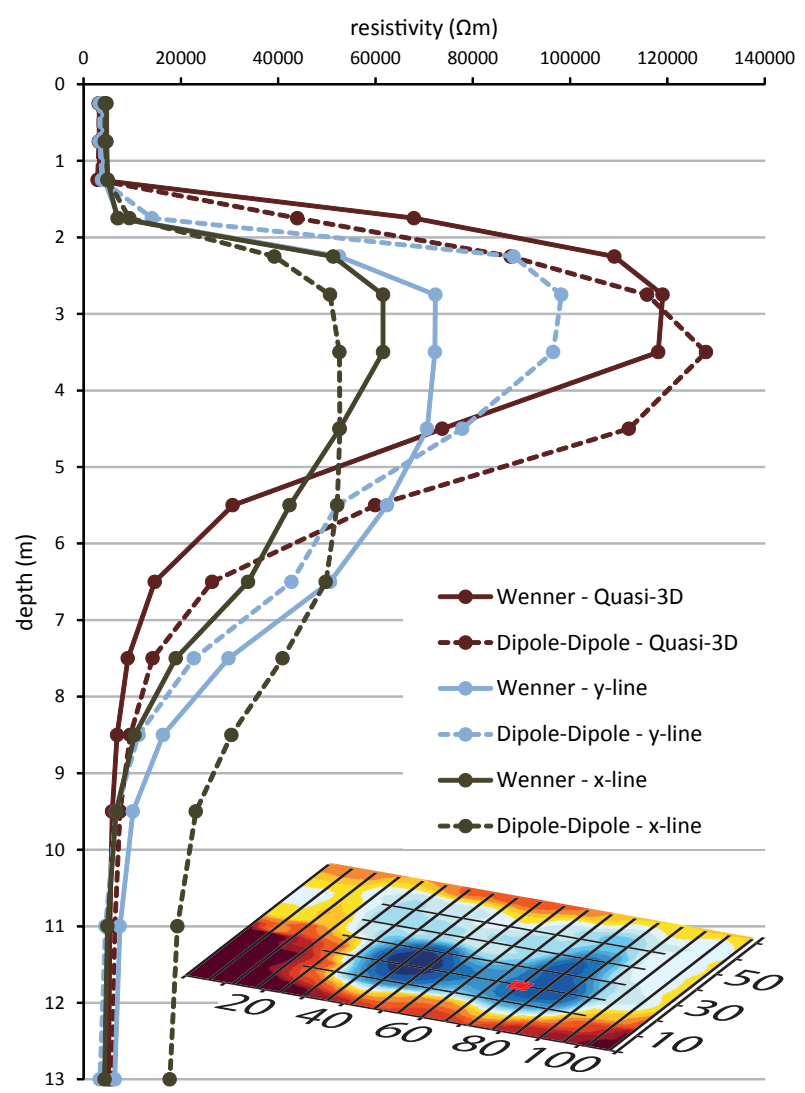

TCD

5, 3383-3421, 2011

\section{Optimisation of quasi-3D ERI for permafrost studies}

D. Schwindt and

C. Kneisel

Title Page

Abstract

\section{Conclusions}

\section{Tables}

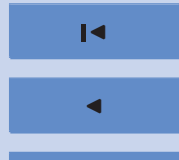

Back
Introduction

References

Figures

- I

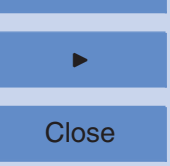

Full Screen / Esc

Printer-friendly Version

Interactive Discussion 